\title{
EL VIAJE, EL TESTIMONIO, LA AMISTAD: ABRAHAM ORTELIUS Y GEORG HOEFNAGEL EN ITALIA (invierno de 1577-78)
}

Jean-Marc Besse

CNRS (Centre national de la recherche scientifique), París

\begin{abstract}
RESUMEN
Desde el siglo XVI, la geografía contribuyó a definir nuestra cultura visual y la manera en la que vemos y representamos el mundo. En el presente artículo se analiza, por una parte, el descubrimiento en ese momento de los lugares mediante el desplazamiento, y, por otra, el cambio que esta manera de conocer produjo en las representaciones del territorio, fundamentalmente, de escala y punto de vista. Para ello, se analizan los dibujos y grabados resultantes del viaje por Italia de los flamencos Abraham Ortelius, erudito geógrafo, marchante de arte y antigüedades, y Georg Hoefnagel, artista. El corpus fruto de sus esfuerzos da forma al considerado primer gran atlas urbano de Europa, el Civitates orbis terrarum. Se trata de vistas frontales que se centran en lo singular, corografías que presentan dos tipos de mirada hacia el territorio: el de la gente local que se integra en su entorno, formando parte del mismo; y el de los viajeros que se representan como observadores de una realidad concreta. Las imágenes de G. Hoefnagel se convierten en demostración de lo experimentado en el viaje y soporte para su narración
\end{abstract}

Palabras clave: paisaje, experiencia geográfica, viaje a Italia, siglo XVI, Abraham Ortelius, Georg Hoefnagel

ABSTRACT

Geography has defined our visual culture and the manner in which we see and depict the world since the 16th century. This article analyses the discovery of places at this time as a result of travel and the change that this way of acquiring knowledge brought about in depictions of the landscape, essentially in terms of scale and viewpoint. The paper will thus study the drawings and etchings resulting from the trip to Italy made by the learned Flemish geographer and art and antiques dealer Abraham Ortelius and the Flemish artist Georg Hoefnagel. The body of work they produced gave rise to what is regarded as the first great urban atlas of Europe: the Civitates orbis terrarum, which comprises frontal views that focus on the exceptional, arrangements that offer two types of view of the landscape: that of the local people who form part of it, and that of the travellers themselves, who are portrayed as observers of a specific reality. Hoefnagel's images are a demonstration of what has been experienced on the journey and a device employed for narrating it.

Keywords: landscape, geographical experience, travel to Italy, 16th century, Abraham Ortelius, Georg Hoefnagel

Cuando uno se pregunta por el papel jugado por la geografía en la formación de las culturas visuales del siglo XVI, el análisis de las relaciones entre las formas de mirar y los tipos de representaciones del espacio supone un momento decisivo. Conocemos las relaciones que existen entre, por un lado, la aparición de un género concreto de pinturas paisajistas (especialmente aquellas que han sido bautizadas como «paisajes del mundo» por los historiadores del arte) y, por otro, la emergencia de un nuevo concepto de globo terráqueo en los conocimientos geográficos del siglo XVI, más concretamente el desarrollo de un nuevo concepto geográfico de la 
Tierra: la Tierra universal. ${ }^{1}$ Las representaciones pictóricas del paisaje (Brueghel, Patinir, Met de Bles) expresan a su manera esta modificación del marco espacio-temporal de la vida humana. Más concretamente, lo que está en juego, conjuntamente, en los registros de la cosmografía y la pintura -unos registros que no son tan distintos a fin de cuentas- es una transformación de las condiciones espacio-temporales de la experiencia geográfica. Se trata de una transformación de notable importancia en el sentido de que tiene un alcance que podríamos calificar de antropológico, que se corresponde con un enriquecimiento, decisivo para la época moderna, de la idea de mundo. Lo que se ofrece en estos momentos a la vista y al pensamiento, tanto en los mapamundis como en los "paisajes del mundo», es el espacio abierto, la horizontalidad de ese espacio, por decirlo así, su capacidad de recorrido infinita, sus pliegues ocultos y por descubrir, y, sencillamente, su positivismo narrativo.

Tanto en la cartografía como en la representación del paisaje, observamos entonces una misma voluntad de dejar constancia de la profusión del mundo y de las experiencias que ahora resultan posibles. Ante todo, observamos una voluntad análoga, en el campo gráfico, de conjugar los distintos aspectos del mundo dentro de un espacio unificado, el espacio terrestre pensado como un todo. Es la circulación -el desplazamiento tanto de personas como de cosas- la que establece esta relación general de los aspectos y de los lugares del mundo. En estos panoramas todo nos habla de los viajes. Las aves y otros animales, los navíos de todo tipo, los vehículos, los peatones y los caballeros... se trata de toda una población que parece atravesar la superficie terrestre en todas direcciones. El mundo es un espacio en el que se circula. $Y$ ese propio mundo está animado por movimientos reales y posibles, como lo demuestran las nubes, los ríos, los caminos que atraviesan las montañas y el horizonte abierto.

La presencia simultánea dentro de la serie de Grandes paisajes de Brueghel de dos tipos de personajes ubicados en dos partes claramente separadas de la imagen -y cuyas actitudes y miradas aparecen contrapuestas pero también relacionadas- es, en este sentido, muy signifi- cativa. Entre estos personajes, unos observan el mundo exterior, el paisaje, y otros se vuelven para sumirse en la contemplación de un discurso y de una historia ultramundanos, aunque, en el fondo, ni unos ni otros pertenecen al mundo en el que son vistos, ya sea porque simplemente están de paso (peregrinos, mercaderes, soldados), ya sea porque se excluyen de él para permanecer en el desierto. Todos ellos parecen encarnar de forma ejemplar, en su propia distinción, un interrogante acerca de las transformaciones antropológicas y psicológicas de los marcos de la experiencia geográfica. En todo caso, permiten plantearse una serie de preguntas: ¿por qué habría que observar el mundo terrestre?, ¿qué habría que ver?, ¿cómo podemos verlo? Son preguntas que pueden parecer un poco genéricas, pero da la impresión de que son asumidas por los propios personajes mientras seguimos su evolución, mientras observamos su descanso y, sobre todo, mientras podemos seguir su mirada en la imagen.

En su A lo largo del camino, Julien Gracq se topa con un interrogante equivalente mientras hojea una selección de grabados de Durero. ${ }^{2}$ Es casi imposible, escribe, imaginarse

lo que eran entonces [en el siglo XVI] las carreteras, los caminos; no tanto su disposición técnica sumaria [...] sino su relación viva con las ciudades, con los pueblos que unían, con los paisajes que atravesaban, con los setos y las cercas, los bosques, los cursos fluviales, el movimiento también de sus usuarios... (p. 147).

«¿Cómo -se pregunta entonces Julien Gracq- se veía la Tierra a lo largo de esos caminos cuando uno la recorría?» (p. 148), añadiendo que probablemente nunca la tierra de Europa fue tan hermosa como en esa época en la que «los caminos profanos están por primera vez abiertos en todas partes» (p.148). Y concluye: "iCómo me hubiera gustado hacer el camino de uno de esos pintores holandeses o alemanes que bajaban embriagados hacia Italia...! » (p. 148).

Es una embriaguez análoga la que nos gustaría seguir aquí, la de un dibujante y de un geógrafo, Joris (o Georg) Hoefnagel y Abraham 
Ortelius, ambos flamencos, ambos amigos de Brueghel y admiradores de Durero (Ortelius ha reunido dos selecciones con varias decenas de dibujos y grabados del «viejo maestro alemán», como lo llama Julien Gracq), ambos grandes viajeros por Europa, ambos huyendo en cierta medida de Amberes o, en todo caso, deseando alejarse de allí (de manera definitiva en el caso de Hoefnagel), tras el saqueo de la ciudad por los españoles en noviembre de 1576, para ir hacia una tierra, Italia, que tiene para ellos, como para muchos otros, el aspecto de un lugar ideal. ${ }^{3}$

Este viaje hacia Italia y en Italia tiene lugar entre finales de septiembre de 1577 y finales de marzo de 1578 y lleva a los viajeros desde Fráncfort hasta los alrededores de Nápoles. Sin embargo, lo que sabemos de este viaje coloca al historiador un poco en la posición de Julien Gracq con respecto a Durero: dan testimonio de ello apenas una veintena de grabados, publicados en Colonia a partir de 1580 en los volúmenes del Civitates orbis terrarum de Georg Braun y Franz Hogenberg, que se puede considerar el primer auténtico atlas urbano de la época moderna en Europa. Los dibujos de Hoefnagel no son los únicos que representan las ciudades italianas en la recopilación de Braun y Hogenberg (ésta incluye varias decenas de perspectivas de ciudad, publicadas en seis volúmenes en 1572 y 1618). No obstante, presentan dos rasgos característicos: por un lado, son vistas frontales y, por decirlo así, peatonales, y no imágenes a vista de pájaro como la mayoría de las demás imágenes de ciudades que contiene la recopilación; y, por otro, las vistas dibujadas por Hoefnagel contienen, como los paisajes de Brueghel, personajes ocupados en actividades diversas, de las que el artista se presenta en varias ocasiones como testigo ocular. Sin embargo y ante todo, entre estos personajes que pueblan las imágenes, dos individuos aparecen en varias ocasiones y llaman la atención: se trata de los propios Ortelius y Hoefnagel, designados como tales en la leyenda de las imágenes, que atraviesan los paisajes italianos en su camino hacia el sur. ¿Qué hacen en la imagen? ¿A qué se dedican? ¿Qué observan los dos viajeros en el paisaje? Esas son las preguntas que nos gustaría plantearle a esta serie de grabados.

\section{Atravesar Italia}

Antes de nada, comentemos brevemente la realidad de este viaje y de sus protagonistas. ${ }^{4}$ De hecho, las situaciones respectivas de Ortelius y Hoefnagel no son en absoluto comparables. En 1577, Abraham Ortelius ya ha logrado una notoriedad considerable por diversos motivos. En primer lugar, es el autor de una obra que ha tenido un gran éxito comercial, especialmente en Italia: el Theatrum orbis terrarum, generalmente considerado el primer atlas de forma moderna. Pero además es un gran comerciante de obras de arte y de mapas, un erudito anticuario y un coleccionista aplicado en varios campos: el de la numismática (su colección es un modelo para muchos de sus coetáneos), el de las artes del dibujo (es amigo de Brueghel y de muchos otros artistas flamencos) y, por último, el de la toponimia antigua (realiza tres diccionarios considerados como fundamentales por sus contemporáneos, concretamente Juste Lipse o John Dee). Es muy probable además que la estancia en Italia, durante el otoño y el invierno de 1577-78, sea para él la ocasión de avanzar en sus investigaciones en estos diversos terrenos. La situación de Joris (o Georg) Hoefnagel en esa misma época es bastante diferente. Hoefnagel pertenece a una de esas familias amberinas de confesión protestante a las que la Furia española (El saqueo de Amberes) de 1576 ha arruinado en parte y les ha obligado a emigrar, hacia Alemania o Inglaterra principalmente. Según Karel Van Mander, es en ese momento cuando decide irse para instalarse en Venecia. ${ }^{5}$ Sin embargo, el viaje a Italia en compañía de Ortelius va a resultar decisivo para el pintor y dibujante amberino y le va a conducir finalmente a otro lugar, a Múnich primero, a la corte del duque de Baviera Alberto $\mathrm{V}$, y a la corte del emperador Rodolfo II después (Fráncfort y posteriormente Viena). Será después del período del viaje en Italia cuando la carrera de Hoefnagel como miniaturista e ilustrador de manuscritos realmente avance.

Sea como fuere, el desplazamiento hacia Italia va a permitir que nuestros dos viajeros visiten algunas de las grandes colecciones europeas de la época: en Augsburgo la del banquero bibliófilo Marx Fugger y la importante colección de monedas de Adolf Occo, en Múnich la colección 
de obras de arte del duque de Baviera (gracias a una carta de presentación de Fugger y de Occo) y la de Alessandro Farnese en Roma. Existen testimonios de la presencia de Ortelius en Ferrara el 30 de octubre de 1577, cuando conoce a Pirro Ligorio. También se habla de que pasan por Florencia. Asimismo, no parece imposible que pasasen por la colección del archiduque Fernando II en el castillo de Ambras de Innsbruck ni que visitasen Caprarola.

A excepción del relato de Van Mander, sigue siendo difícil establecer la realidad concreta del trayecto y la estancia. Desde luego, disponemos de algunas fechas que permiten enmarcar las hipótesis: Ortelius se encuentra el 20 de septiembre en Fráncfort, el 7 de octubre en Augsburgo y el 30 en Ferrara (según las inscripciones de su Album amicorum), Hoefnagel está el 24 de diciembre en Pesaro y el 20 de abril de 1578 de vuelta en Múnich (algo que anota él mismo en los dibujos preparatorios de los grabados). ${ }^{6}$ Los dos hombres visitan juntos Tívoli el 1 de febrero de 1578, si creemos la inscripción que aparece en el grabado publicado en el Civitates orbis terrarum.

A fin de cuentas, la principal fuente en la que uno puede basarse para seguir el viaje está formada por la serie de grabados publicada en la recopilación de Braun y Hogenberg. Una serie que presenta evidentemente un sesgo: el orden en que se presentan las imágenes dentro de la recopilación no se corresponde en absoluto con el desarrollo real del desplazamiento, concretamente en la parte relativa al norte de Italia, sobre la que existen muchas incertidumbres: ¿Fueron juntos nuestros dos viajeros hacia Roma siguiendo la Vía Flaminia? ¿O acaso se separaron (téngase en cuenta que Hoefnagel indica, en la parte baja del grabado que representa el incendio del Palacio de los Dogos de Venecia, que lo presenció; puesto que este incendio se produjo el 20 de diciembre de 1577, esto otorgaría cierta coherencia a la fecha del 24 de diciembre para la vista de Pesaro)? ¿O acaso aún podemos decir que Hoefnagel aprovechó su estancia en Roma para acercarse (lo que parece más probable, especialmente porque las ciudades que se representan están situadas en rutas distintas y parece inverosímil que nuestros viajeros hubiesen adoptado un comportamiento tan errático)? Dicho de otra forma, hay que distinguir entre el viaje real y el viaje imaginario que está ordenado por la sucesión de imágenes del Civitates orbis terrarum. La lógica geográfica que en él se despliega es, ante todo, una lógica editorial y descriptiva bajo la que subyace una concepción del espacio centrada en el norte de Europa, desde la que se supone que parte el lector, para ir, en el caso de Italia, hacia el sur. El único «momento» en el que el viaje real y el viaje de las imágenes parece que se superponen es cuando Ortelius y Hoefnagel van de Roma a la región napolitana siguiendo la Vía Apia. Es además el único momento en que vemos, de manera significativa, a nuestros viajeros dentro de las imágenes, realizando actividades diversas relacionadas con el paisaje. Volvamos entonces a nuestras preguntas: ¿Qué hacen Ortelius y Hoefnagel en la imagen?, ¿a qué se dedican concretamente?, ¿qué observan en el paisaje?

Para afrontar estas preguntas podemos apoyarnos, en un primer momento, en una distinción bastante superficial entre dos categorías de personajes presentes en las imágenes: por un lado, los personajes vistos por los viajeros, que se nos muestran como objetos bajo las miradas de los viajeros, y, por otro, los propios viajeros, en este caso los viajeros amberinos, que se nos muestran como observadores, sujetos que observan. Una distinción entre el observado y el observador, entre el objeto y el sujeto, que acompaña y expresa quizás otra distinción: la del interior y el exterior. Dicho de otra forma: una distinción entre personajes que son vistos como parte del paisaje, con independencia de la actividad que desarrollen, y los personajes que no encajan en él, que vienen de otro lugar, del exterior, y que solo están de paso.

\section{Observar Italia}

¿Qué vemos en las imágenes de Hoefnagel ? ¿Cuáles son los personajes que, en la imagen, están en el lado del que es observado, como si perteneciese a los lugares atravesados? Podemos realizar rápidamente el inventario tipológico: son marineros, pescadores, porteadores, pastores, campesinos, mujeres que se ocupan en actividades diversas (ir o volver del mercado, recoger aceitunas, ir a los baños), mendigos, viajeros, lo más habitual personas que circulan por el territorio con o sin animales, turistas quizás, escenas 
galantes o un poco enigmáticas, vendedores de objetos arqueológicos... (Figuras 1).

Estos diversos grupos humanos ayudan a animar $y$, ante todo, a caracterizar los paisajes en los que se les ve. Una precisión: a todos estos personajes, con la excepción de Venecia, no se les ve en la ciudad, que sin embargo constituye el centro de la imagen y la razón de ser de los grabados. Salen o llegan a ella, están ocupados en diversas tareas en torno a la ciudad. Pertenecen al territorio. En este sentido, podemos hablar de una especie de "naturalización» de las actividades humanas en las descripciones gráficas realizadas por Hoefnagel. Habría sin embargo que precisar el sentido de esta expresión. De hecho, se ha mencionado con frecuencia, tras el artículo de Ernst Kris sobre Hoefnagel y el naturalismo científico, el realismo y el didactismo de las vistas topográficas del dibujante flamenco. ${ }^{7}$ La dimensión de la autopsia, del testimonio visual, de la «toma del natural», de la experiencia vivida, está con frecuencia presente en las leyendas de los dibujos de Hoefnagel, que, durante sus viajes, como escribe Van Mander, había recopilado «un gran volumen de todo aquello que le chocaba: escenas rústicas, lagares, obras hidráulicas, escenas de costumbres: bodas, bailes, fiestas, etc.» (p. 62). Es lo que sucede en Italia. También es lo que ocurre en los numerosos dibujos realizados en España que igualmente encontramos en el Civitates orbis terrarum.

No vamos a entrar aquí en el comentario del significado de la divisa Natura sola magistra (la naturaleza es mi única maestra) utilizada por Hoefnagel. ${ }^{8}$ Querríamos sobre todo volver a colocar las imágenes del dibujante flamenco en el contexto del proyecto intelectual y editorial en el que se hicieron públicas, tras haber sido encargadas en la mayoría de los casos (es decir, el contexto del Civitates orbis terrarum). Este proyecto es enunciado muy explícitamente por el diseñador de la obra (Georg Braun) en referencia al Theatrum orbis terrarum de Ortelius en primer lugar, pero principalmente en el marco de una
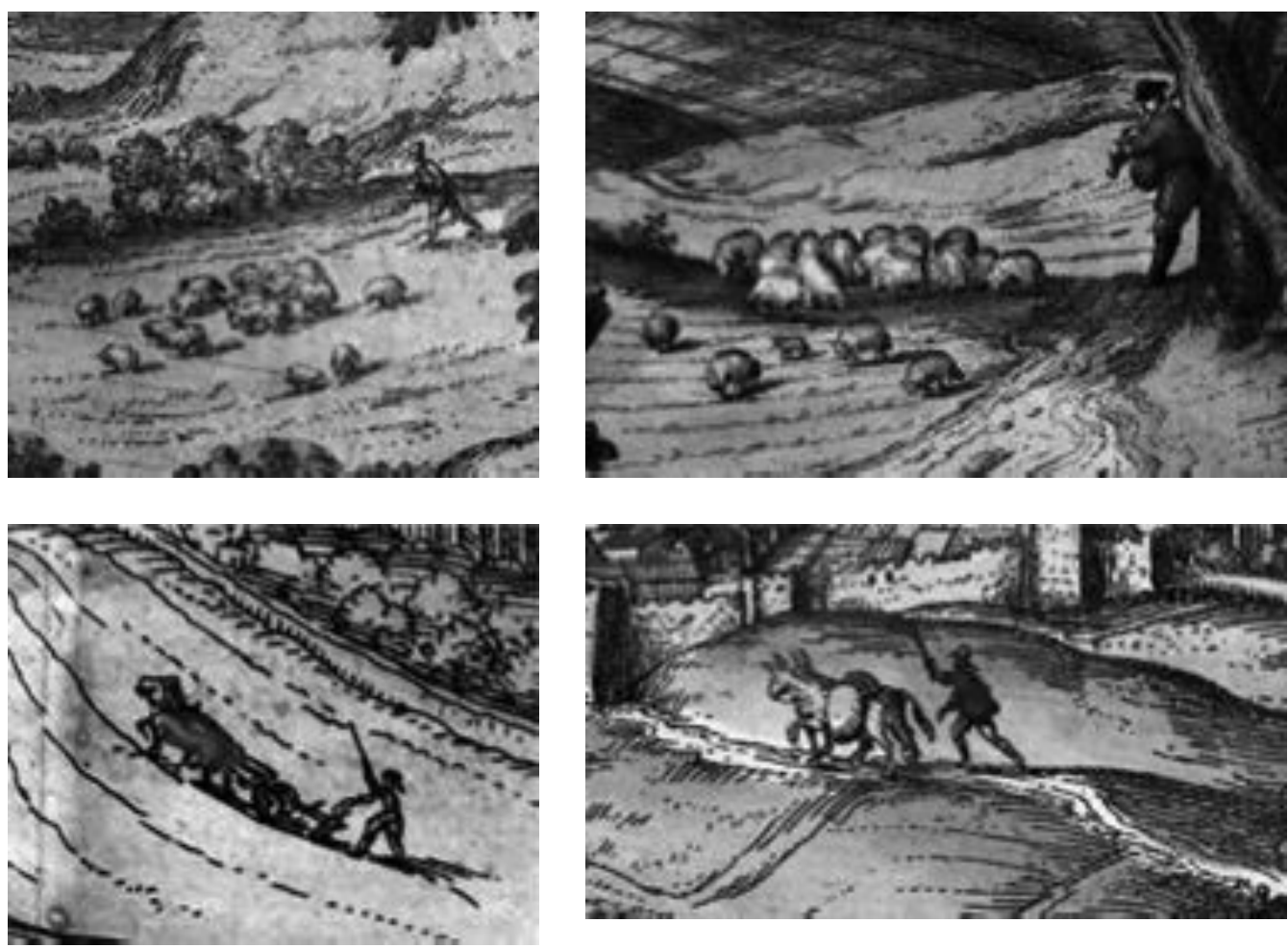

Figuras 1. Ilustraciones del Civitates Orbis Terrarum, de Georg Braun, Colonia, 1578-1618, 6 vol. (ejemplar de la Biblioteca Municipal de Lille, signatura: 44403). 


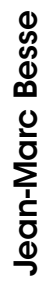
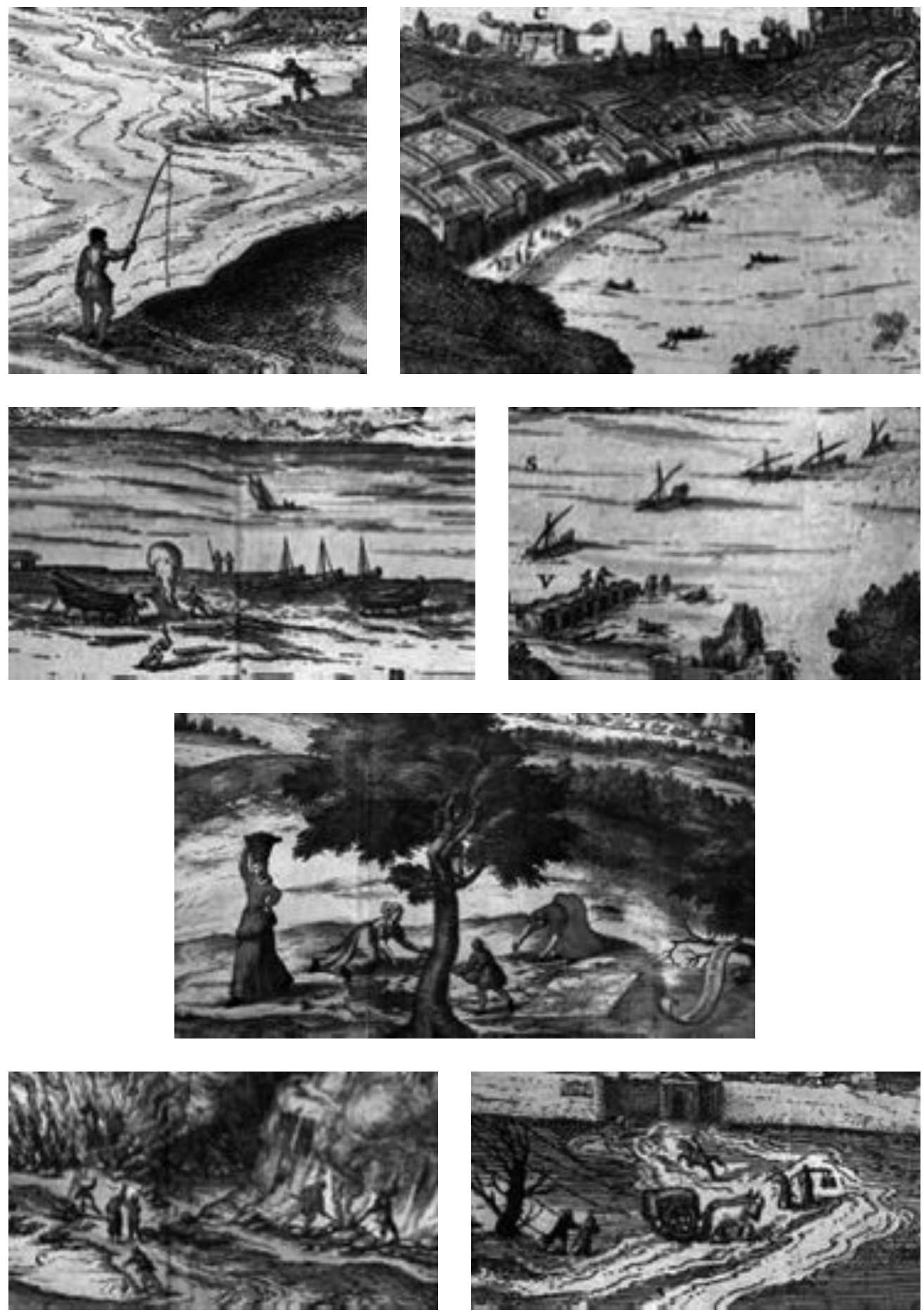

Figuras 1. Ilustraciones del Civitates Orbis Terrarum, de Georg Braun, Colonia, 1578-1618, 6 vol. (ejemplar de la Biblioteca Municipal de Lille, signatura: 44403). 
distinción conceptual que sigue siendo la de Tolomeo: la distinción entre geografía y corografía. El atlas de Ortelius es una obra de geografía, en el sentido de que su objetivo es la representación del mundo terrestre a pequeña escala, el objetivo del mapamundi. Al pretender colocarse junto al Theatrum orbis terrarum, y en una especie de paralelo con él, la obra de Braun y Hogenberg (Civitates orbis terrarum) aspira a encargarse de la representación del mundo a gran escala, es decir, al nivel de los lugares. Esta escala es la de la corografía y la topografía (ambos términos se solapan parcialmente). Dicho de otra forma, si Ortelius es geógrafo o cosmógrafo, Hoefnagel será corógrafo o topógrafo.

La distinción entre geografía y corografía (o topografía) no es únicamente una distinción de escala (lo global frente a lo local). ${ }^{9}$ Remite también a un principio de método y a una práctica diferenciada de la representación. El enfoque geográfico, se dice entonces tras la aportación de Tolomeo, es geométrico, se preocupa por la exactitud de las localizaciones, las distancias y los lugares, y por la conformidad en el dibujo de los límites y las formas de los territorios. Según el vocabulario de la época, todo esto plantea una inquietud, la de la cantidad. El enfoque corográfico es diferente. Éste aspira a representar las cualidades características de un lugar, sus propiedades singulares, siguiendo el método del retrato mediante la «exposición concreta -como dice Braun en el prefacio del libro III- de la historia de determinadas partes del mundo, [...] poniéndolas ante los ojos de los observadores, como si observasen los propios lugares», ${ }^{10}$ o bien, como dice un contemporáneo, Antoine du Pinet,

mostrando únicamente al ojo, lo más próximo a la realidad posible, la forma, el emplazamiento y las dependencias del lugar que describe: cómo serían las fortalezas, las ciudadelas, los templos, las calles, las plazas, los coliseos, las plazas de toros, los canales, los viveros, los puertos, los malecones y otras edificaciones simbólicas que podrían estar en una ciudad, con el paisaje colindante $y$ sus idas y venidas. ${ }^{11}$

Si el geógrafo o el cosmógrafo consideran el globo terráqueo de lejos, desde el cielo, por decirlo así, el corógrafo procura ver los lugares de cerca.

Volvamos a los personajes de Hoefnagel. Pero, para volver a ellos y comprender su presencia, detengámonos en la expresión «paisaje colindante» de una ciudad, utilizada por Du Pinet. Él mismo, poco después, hablará del «paisaje de un lugar» y del «paisaje de un país». El término «paisaje» no tiene aquí una significación especialmente artística, incluso aunque pueda ser asumido por el dibujo y la pintura. Designa un espacio visible o, con más precisión, el aspecto o más bien los aspectos visibles del país, del lugar o del territorio que rodea la ciudad, el ager y quizás el saltus por oposición a la urbs. Remite a lo que un viajero y un observador pueden encontrar cuando recorren el lugar o el país: una geología, accidentes del terreno, colores, campos cultivados, carreteras, ciudades, casas, vestigios del pasado, seres humanos. Señalemos, aunque no nos podamos parar en ello, que las imágenes de Hoefnagel están acompañadas de un texto que aporta una explicación de lo que vamos a descubrir en ellas. Es un texto que normalmente está compilado a partir de la descripción de Italia de Leandro Alberti y que otorga al lugar representado una especie de profundidad histórica o mitológica. ${ }^{12}$

El paisaje dibujado por Hoefnagel es por tanto un espacio vivido, trabajado, construido, atravesado, en resumen, el espacio de un conjunto de vidas ordinarias: un paisaje humano y no solo una topografía natural o un espectáculo grandioso. Los personajes representados forman parte del paisaje, pero porque habitan y caracterizan un espacio (el de Italia en este caso) que también es vivido por el dibujante que lo recorre.

Dicho de otra forma, las imágenes de Hoefnagel desarrollan una concepción del espacio (y del paisaje) que podemos denominar corográfico (más que geográfico en el sentido estricto del término): no se trata, como en el caso de la cosmografía o de la geografía de una mirada que domina la tierra, sino más bien de una visión o una construcción del espacio terrestre que se hace de cerca, a ras de suelo (por así decirlo), a partir de los lugares atravesados y vistos de cerca por el homo viator. El espacio de los paisajes de Hoefnagel es una colección de lugares, acciden- 
tes y singularidades. Los personajes que allí se encuentran forman parte de esas singularidades que otorgan al paisaje su densidad particular.

\section{III. ¿Criticar Italia?}

¿Qué sucede entonces con los personajes que en las imágenes se nos muestran como ajenos a los lugares y paisajes en los que los vemos? ¿Qué sucede con los que están de paso? ¿Qué sucede concretamente con los viajeros que son Abraham Ortelius y Joris Hoefnagel? Como ya hemos señalado, Hoefnagel documenta sobre todo el trayecto entre Roma y Nápoles y la estancia en Campania. Volvamos una vez más a nuestras preguntas iniciales que ahora es posible realizar a las imágenes que los representan: ¿qué hacen los viajeros flamencos en estas imágenes?, ¿qué hacen en Italia?

Una primera respuesta sería la siguiente: se dedican a cosas muy diversas (Figuras 2). Dibujan (Verona), charlan (Velletri, Nápoles), admiran (Pozzuoli, Gaeta), realizan observaciones y acumulan experiencias (lago de Agnano) o conmemoran (Tívoli). Ambos viajeros flamencos visitan Italia con la actitud del placer erudito, propia quizás de los anticuarios del siglo XVI. Sin embargo, la mirada que Ortelius y Hoefnagel ofrecen de Campania es más compleja de lo que podría parecer.

De hecho, es una mirada doble, que mezcla los recuerdos de lecturas y las observaciones sobre el terreno; unas lecturas y unas observaciones que en ocasiones se contradicen. Por consecuencia, es una mirada ambivalente en la que, al placer de recorrer concretamente una tierra legendaria, la propia experiencia de los lugares añade el argumento de una toma de distancia crítica.

Por tanto, por un lado está la alegría de estar allí que expresan las imágenes (la admiración e incluso la adoración que se ve en las actitudes de los personajes) y las leyendas que las acompañan. Ortelius y Hoefnagel se incluyen sin ambages en el topos de la Campania felix (Fig. 3), como indica el texto que da título a la vista de Bayas: Nullus in Orbe Locus Baijs praelucet amoenis (la edición en francés de 1618 lo traduce: «No existe otro lugar mejor en el mundo que la agradable Bayas»).
No obstante, por otro lado, la mirada se vuelve más inquisitiva, más observadora, más experimental, marcando así una especie de toma de distancia crítica con las tradiciones de la antigüedad. Lo vemos concretamente en la plancha que presenta dos vistas, el lago de Agnano por una parte y Cumas por otra, conocida por acoger la cueva de la Sibila (Figuras 4).

En el marco superior, el texto indica que el nombre del lago viene del griego aorgnon, que significa «sin pájaros». Según Virgilio, la ausencia de aves se debe a los vapores mortales que emanan del lago, donde se creía que estaba la entrada a los infiernos, vapores que tendrían el poder de matar a los pájaros que sobrevolasen el agua. ${ }^{13}$ En el centro de la imagen se encuentran los dos viajeros, uno señalando con el dedo a los pájaros que nadan en el lago, mientras que el otro toma notas, quizás aquellas que leemos a su derecha o en el comentario que acompaña a la plancha: Ortelius y Hoefnagel «han sabido por cierta experiencia que este lago no es aorgnon». La observación sobre el terreno entra en contradicción con el texto de Virgilio.

Sin duda, habría que relacionar esta doble mirada con la actitud adoptada por Ortelius en el terreno de la historia y de los conocimientos anticuarios. Ahí encontramos el mismo tipo de ambivalencia con respecto al pasado tal y como lo leemos en los textos antiguos.

Por un lado, de hecho, el mapa (y más generalmente la imagen geográfica) se define como un instrumento que permite leer y comprender las historias (es el sentido de la fórmula de Ortelius que se encuentra al comienzo del Theatrum orbis terrarum o en el frontispicio del Parergon: la geografía es el ojo de la historia). En este sentido, la imagen geográfica, puesto que es una herramienta de visualización de la historia, es un soporte para el testimonio del relato. La imagen da fe de lo que dice el texto. Encontramos esta concepción de las relaciones entre imagen, geografía e historia en la obra, por ejemplo en la vista que representa a Ortelius y Hoefnagel de espaldas, delante del golfo de Gaeta, en la que Ortelius señala con el dedo a su compañero una tarjeta en la que se lee una frase extraída del comienzo del libro 7 de la Eneida de Virgilio: Tu quoque litoribus nostris, Aeneia nutrix, aeter- 


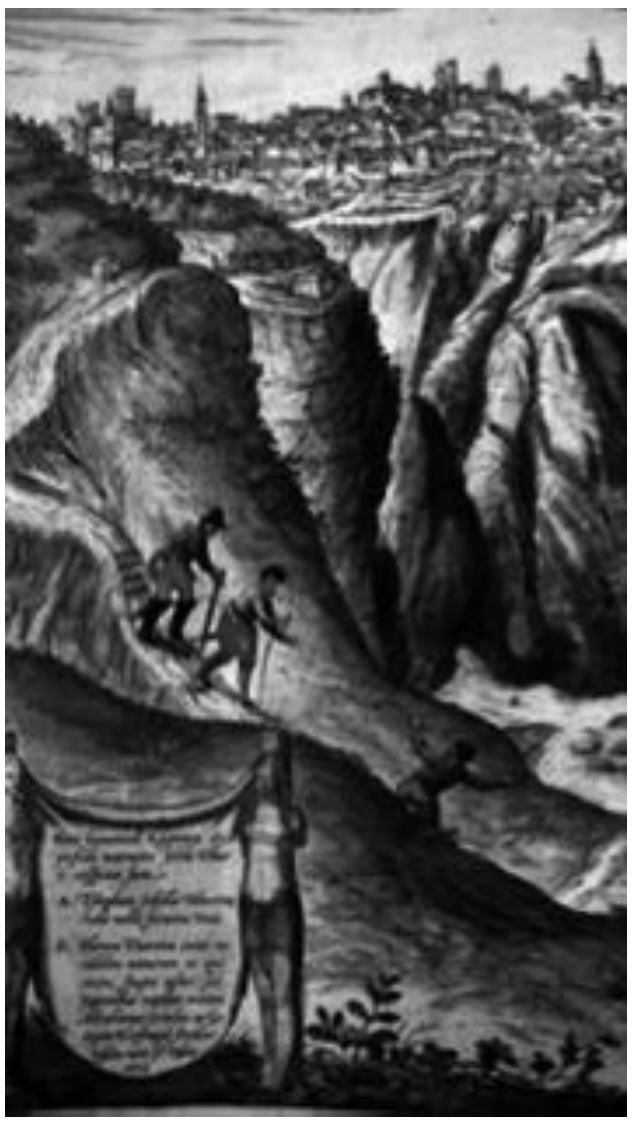

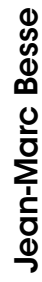
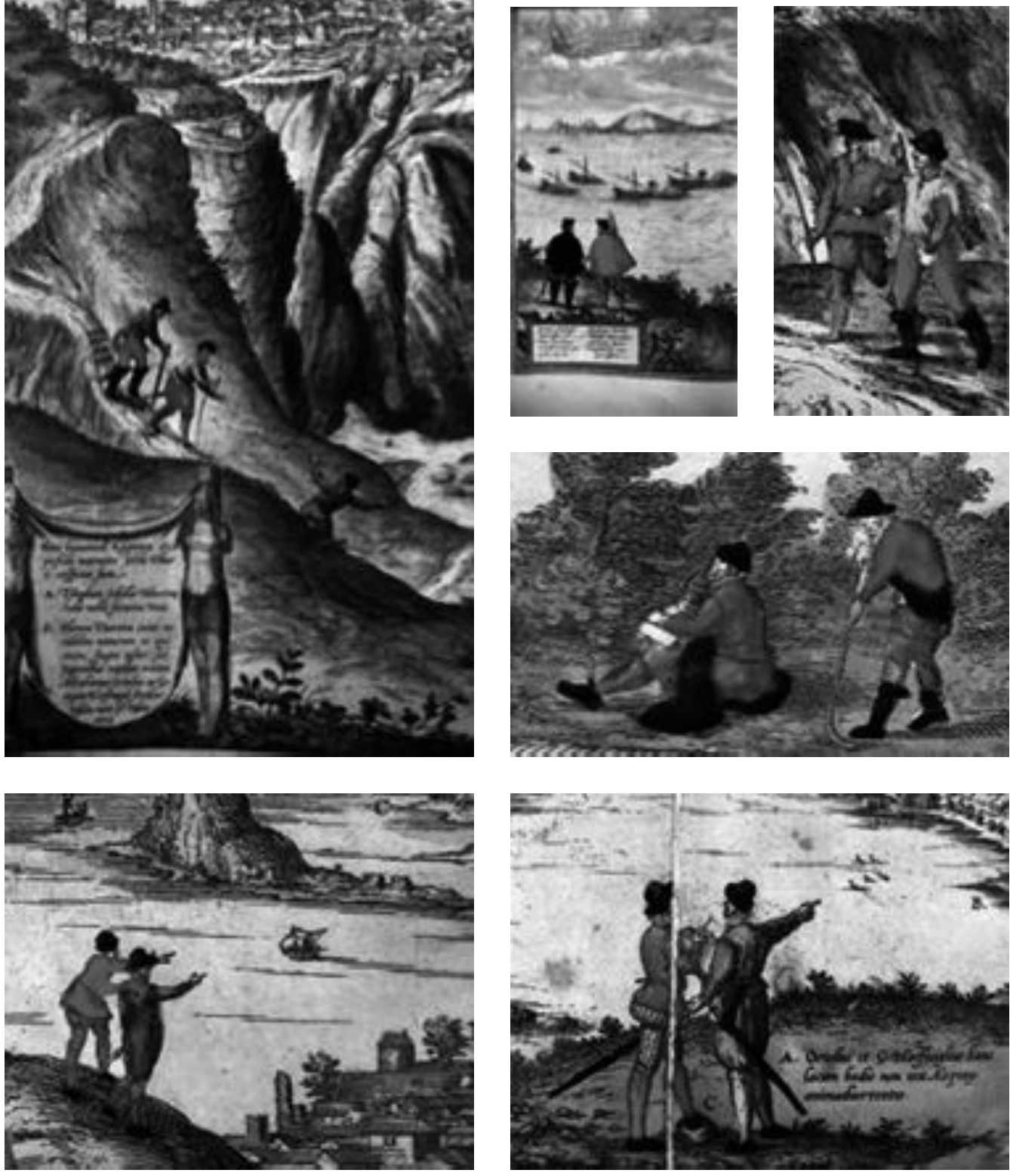

Figuras 2. Ilustraciones del Civitates Orbis Terrarum, de Georg Braun, Colonia, 1578-1618, Biblioteca Municipal de Lille. 


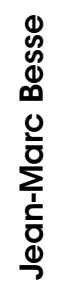

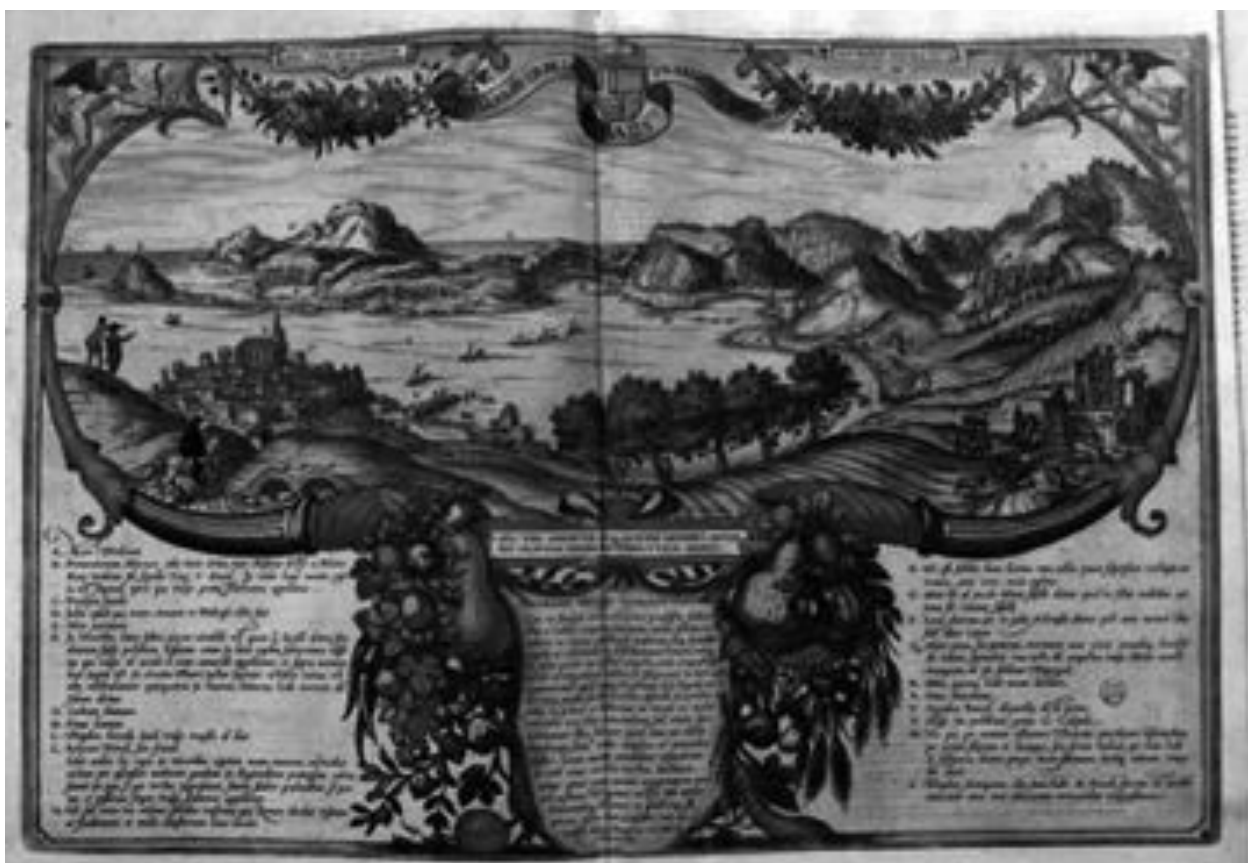

Fig. 3. Ilustración del Civitates Orbis Terrarum, de Georg Braun, Colonia, 1578-1618, Biblioteca Municipal de Lille.

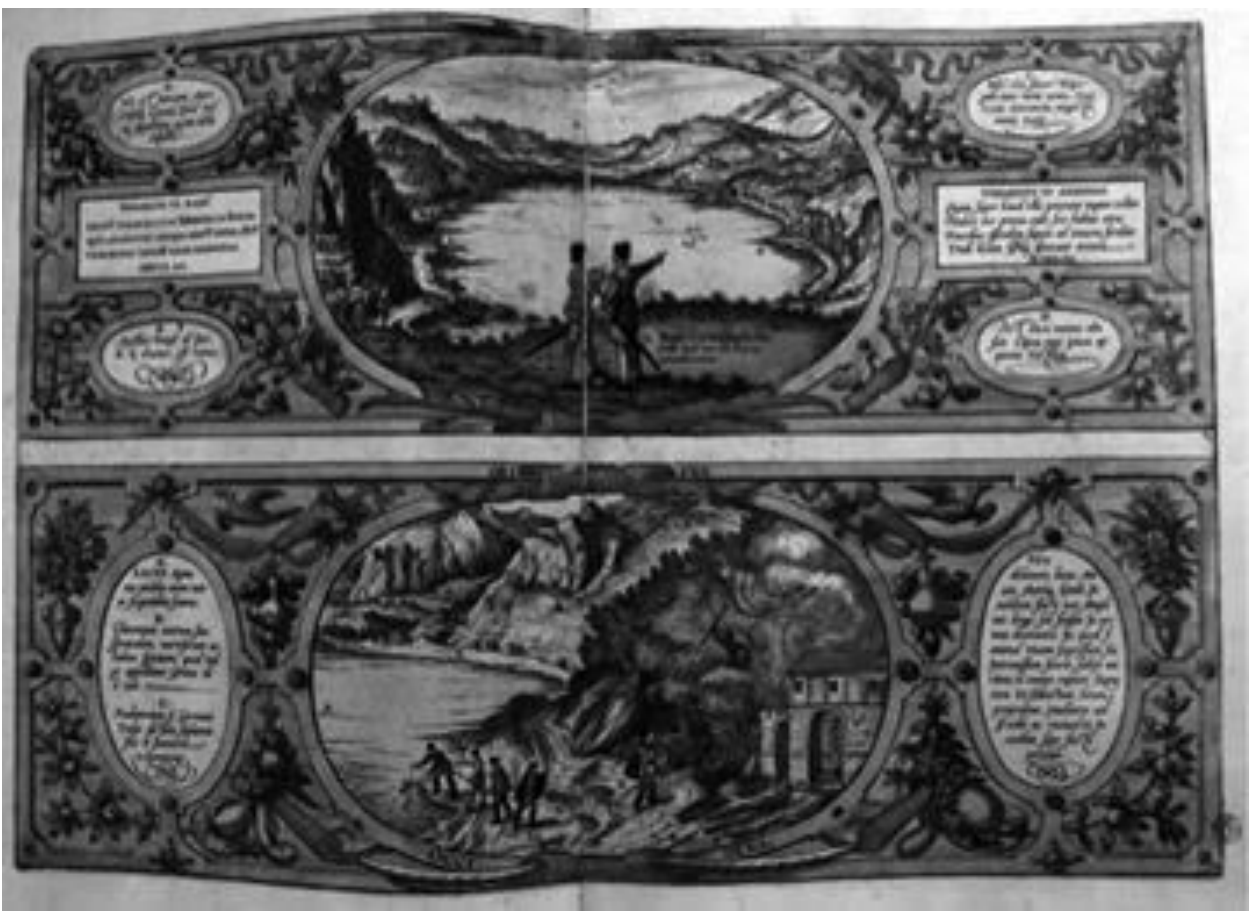




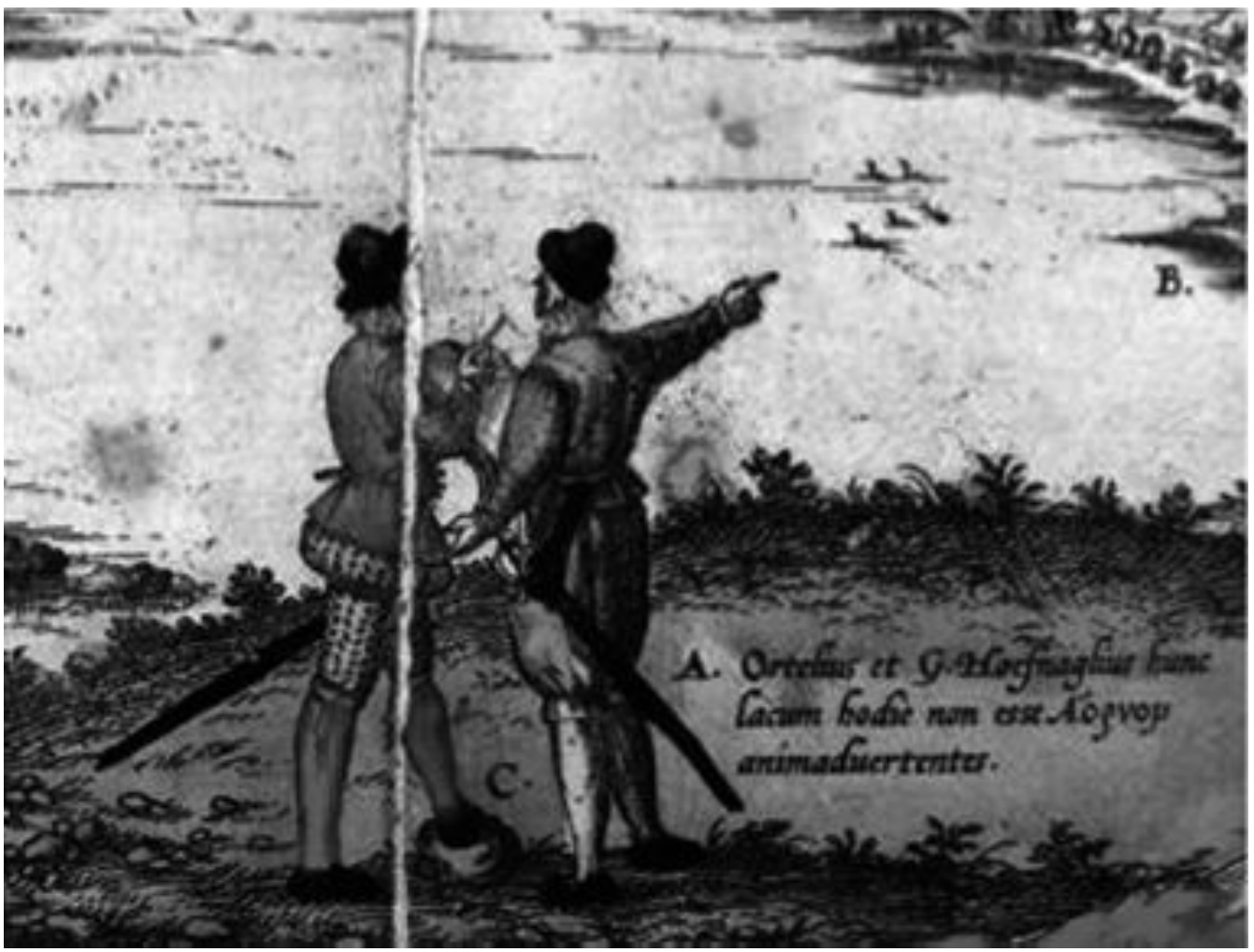

Figuras 4. Ilustraciones del Civitates Orbis Terrarum, de Georg Braun, Colonia, 1578-1618, Biblioteca Municipal de Lille.

nam moriens famam, Caieta, dedisti («Tú también, joh, Cayeta!, nodriza de Eneas, diste con tu muerte eterna fama a nuestras playas» -trad. de E. de Ochoa-: al salir de los infiernos, Eneas abandona Campania y fondea en un puerto del sur del Lacio al que da el nombre de Cayeta, en honor a su nodriza que acaba de morir) (Fig. 5). La imagen muestra el lugar que se menciona en el texto, depende del texto histórico-poético de Virgilio, con el que, en cierta forma, Ortelius y Hoefnagel le piden al lector que se conforme en su imaginación.

Sin embargo, por otro lado, Ortelius recurre a otras estrategias iconográficas en las que asistimos más bien a un verdadero reconocimiento de la imagen como soporte específico, incluso exclusivo, de la información histórica. ${ }^{14}$ Esta «liberación» de la imagen se realiza, en primer lugar, aunque no en exclusiva, en el terreno de la numismática. El Ortelius numismá- tico, pero también editor de mapas históricos, está comprometido, con otros, en la labor de la ampliación del terreno de las fuentes históricas. De hecho, las monedas permiten comprender el sentido de una palabra, de una actividad o de cualquier otra cosa, por comparación del texto en que se han leído con la imagen que la representa. Son como huellas o vestigios del pasado que, en ese momento, se puede garantizar que no son una simple ficción. Además, puesto que muestran los objetos descritos en los textos antiguos, las monedas reaniman la memoria perdida y las devuelven, por así decirlo, al terreno de la experiencia posible. No obstante, ante todo, las monedas, así como las imágenes grabadas que las representan y las ponen en circulación en el mundo erudito, aportan al historiador información que no encuentra en ningún otro sitio. Si, como ha indicado Momigliano en un artículo clásico, «la idea de que podamos escribir una historia de Roma capaz de sustituir a Tito Livio 


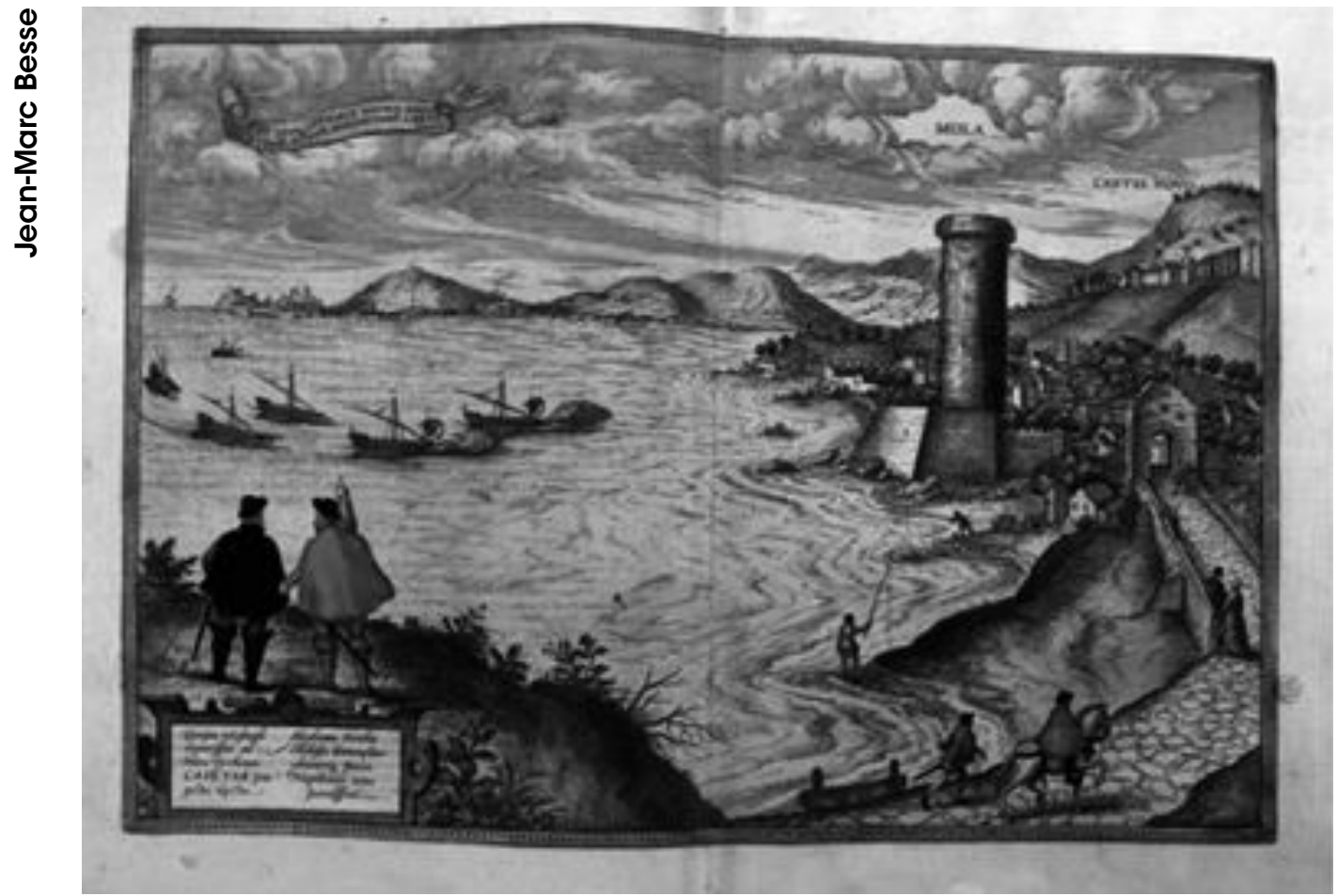

Fig. 5. Ilustración del Civitates Orbis Terrarum, de Georg Braun, Colonia, 1578-1618, Biblioteca Municipal de Lille.

y Tácito todavía no ha nacido» en esta época, ${ }^{15}$ sí que es cierto que no resulta imposible trabajar en los márgenes de los textos antiguos e insertar en ellos nuevos datos obtenidos de la observación sobre el terreno. Igualmente, no resulta imposible demostrar audacia y libertad con respecto al pasado. Podemos preguntarnos si no es lo que indican las actitudes de los personajes de la plancha que los muestra inspeccionando el lago de Agnano, acumulando experiencias y desafiando la amenaza que se erige ante la puerta de la cueva de la Sibila (véase la figura 4).

En cualquier caso, el puñado de imágenes que presentan a Ortelius y Hoefnagel en los paisajes de Campania indican que la relación que mantienen con los lugares y los paisajes de la antigüedad ya no es tan sencilla: sin duda, hay que ir a ver y se alegran de encontrarse allí, pero, al mismo tiempo, aparece una distancia entre lo que ven y lo que saben, entre lo que los libros les habían enseñado y lo que los propios lugares les dicen ahora directamente.

\section{Haber ido a Italia}

Sin embargo, las imágenes que estamos contemplando nos muestran también otras miradas.

Así, en ellas vemos, por ejemplo, a Hoefnagel, que se observa a sí mismo, por así decirlo, o más bien que se muestra en la reivindicación de su identidad de artista, concretamente en su relación con Brueghel, en Tívoli. ${ }^{16}$ Estos grabados no hablan, por tanto, solo de la Italia del siglo $X V I$, ni de un determinado tipo de relación que se deba establecer con el pasado antiguo, sino que hablan también de amistad y de la definición de un cierto tipo de ethos erudito, encarnado aquí por Ortelius frente a Hoefnagel.

La vista de Velletri es, a este respecto, muy significativa (Fig. 6). Esa vista muestra a Ortelius y Hoefnagel acercándose a la ciudad, durante la primera jornada del viaje de Roma a Nápoles (según se indica en el dibujo original). Ambos hombres, que en ese momento no observan el paisaje 


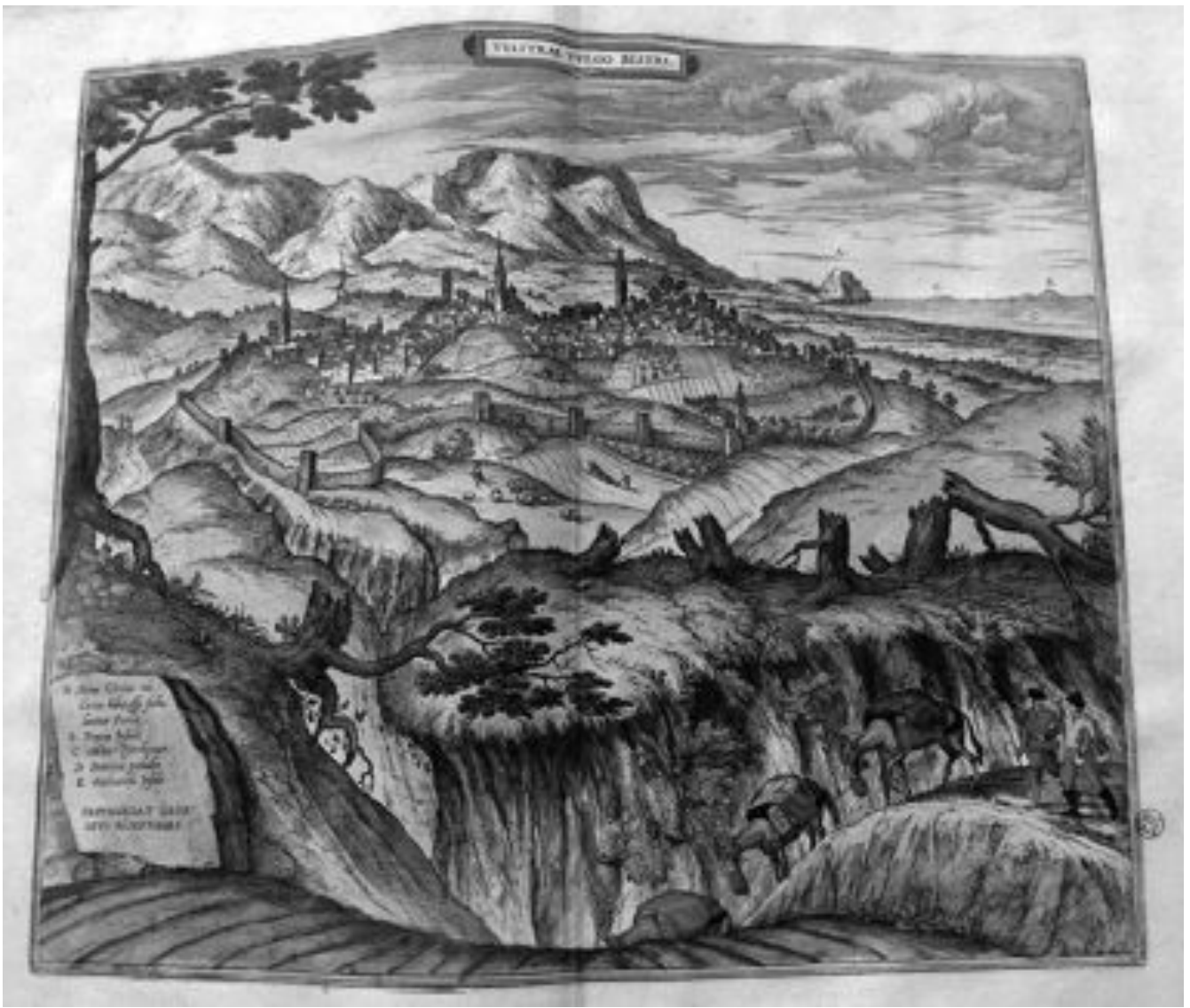

Fig. 6. Ilustración del Civitates Orbis Terrarum, de Georg Braun, Colonia, 1578-1618, Biblioteca Municipal de Lille.

sino que se han vuelto el uno hacia el otro, están aparentemente en una discusión acalorada. Uno (que parece mayor, Ortelius sin duda) señala al cielo con el dedo índice de la mano izquierda, el otro con el dedo índice de la mano derecha señala el suelo, o para ser más exactos, el camino que están siguiendo. ¿Hay que ver en esta imagen, por parte del dibujante (es decir, Hoefnagel), una alusión a la discusión filosófica entre Platón y Aristóteles representada por Rafael en el Vaticano y que ellos quizás hayan conocido? ¿Hay que ver un debate, en esta carretera que se acerca a la ciudad, relativo a las indicaciones que hay que dar con respecto al pensamiento? ¿El cielo o la tierra? ¿Una reflexión sobre la fabricación y el orden del cosmos, o bien un interrogante sobre las reglas de la vida que hay que seguir en la Tierra? ¿Una meditación cosmográfica o una deliberación ética? ¿Qué camino seguir, a fin de cuentas?

No es seguro que haya que elegir. Es posible que sea la coexistencia entre estas dos direcciones la que dota de sentido exacto a la situación humana $y$, ante todo, a la situación cognitiva que se trata en esta imagen. En efecto, es chocante que se relacione lo que se dibuja o se discute mediante estos movimientos de brazos y de miradas en el paisaje italiano con las reflexiones contemporáneas acerca de la situación y la práctica de la propia geografía. Y es que, efectivamente, en juego está el establecimiento en la cosmografía de una relación entre el cielo y la tierra, en el plano matemático y físico, en las definiciones que se le da en el siglo XVI. Una 
mirada unificadora que consiste en una mirada alternada, que primero sube al Cielo y después vuelve a descender a la Tierra para determinar la figura exacta precisa. Henry Hondius ha definido el espacio de trabajo de la cosmografía resumiendo, a su manera, la alternativa que se nos presenta ante Velletri:

Dios nos ha colocado sobre la Tierra y debajo del Cielo; tanto para que al bajar la cabeza observemos la Tierra, como para que al levantar la mirada contemplemos el Cielo. Al mirar hacia arriba y tomar atentamente en consideración esta admirable máquina de esferas celestes, nos convertimos en astrónomos. Al bajar nuestra mirada a la Tierra y ocuparnos de medir su extensión, somos geógrafos. Mediante estas dos ciencias, el hombre se vuelve digno habitante del mundo... ${ }^{17}$

La misma necesidad de pensar conjuntamente el cielo y la tierra, en el marco de la cosmografía, se expresa también en el frontispicio de la edición de Tolomeo realizada en 1578 por Gérard Mercator. Consideremos de hecho los gestos efectuados por Tolomeo, el príncipe de los geógrafos, a la izquierda de la imagen, tal y como está representado por aquel que denominaremos el Tolomeo moderno (Fig. 7).

La mano izquierda señala abajo el globo terráqueo con un compás que lo mide. El índice de la mano derecha está elevado hacia las alturas y señala muy claramente el globo celeste (con las imágenes de las constelaciones), que es el fundamento de las medidas terrestres. Estos dos brazos son como dos miradas. El cosmógrafo es el que conecta, como un intercesor, en el espacio mismo abierto por sus brazos, los dos globos. El propio cuerpo del cosmógrafo, en la imagen, es el lugar en el que se inscribe para la mirada del futuro lector el espacio perceptivo e intelectual de la cosmografía.

¿Cómo comprender, a fin de cuentas, esta actitud de Ortelius y Hoefnagel ante Velletri? ¿Por qué ha decidido Hoefnagel representar así a su compañero?

La hipótesis que vamos a proponer, a modo de respuesta, es la siguiente: Hoefnagel está le-

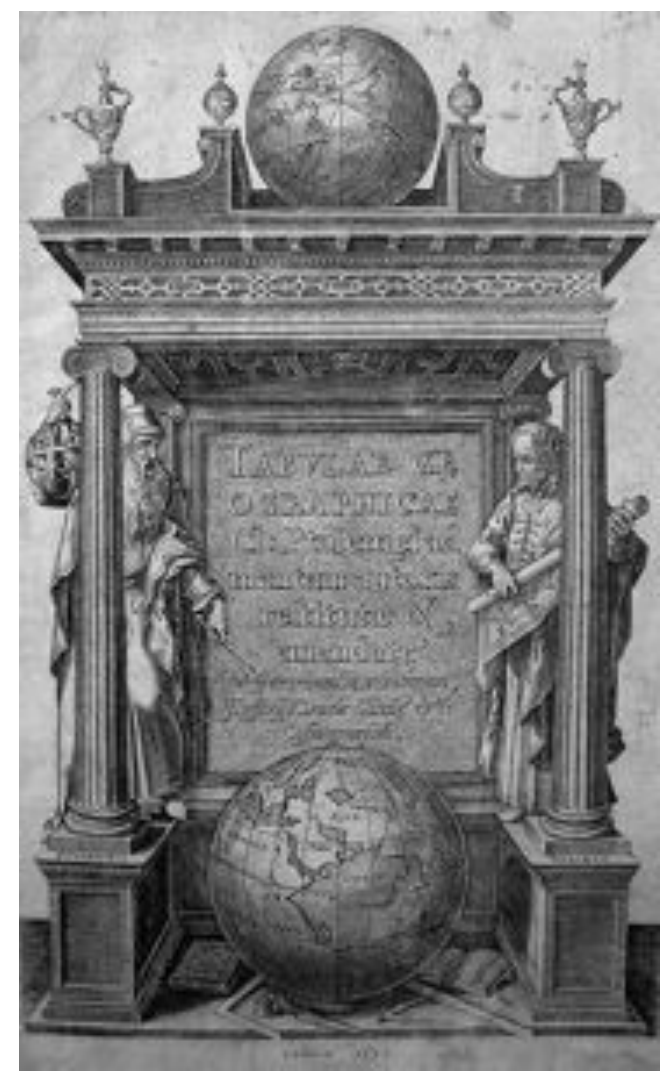

Fig. 7. Frontispicio de Tabulae geographicae Cl. Ptolemaei ad mentem autoris restitutae et emendatae per Gerardum Mercatorem..., Colonia, 1578 (reimpresión en facsímile, Bruselas, Culture et civilisation, 1964, ejemplar de la B.M. de Lille, signatura: 51495).

vantando, en esta imagen y en la serie que expone la estancia en Campania, un monumento a la amistad para Ortelius. ${ }^{18}$ Varios indicios refuerzan esta hipótesis. En primer lugar, los propios textos, colocados por Hoefnagel sobre los retratos de Ortelius. En Gaeta, Ortelius, descrito como un compañero de viaje muy agradable, es, ante todo, studiosus contemplator, una expresión que determina aquí el tipo de mirada que Ortelius dirigiría a los paisajes atravesados y al mundo en general, y que habría que relacionar indudablemente con las analogías presentadas por otros amigos del geógrafo flamenco para dibujarlo, especialmente con la imagen de Apolo. Esta imagen apolínea es utilizada con frecuencia para representar el trabajo del cosmógrafo del 
siglo XVI y el propio Ortelius la usará en el Parergon, su recopilación de cartografía histórica.

La plancha que representa a Bayas, enviada como regalo en marzo de 1580 por Hoefnagel a Ortelius, contiene en su parte central un texto que merece un largo comentario (véase la figura 3). En efecto, más allá de la afirmación de la amistad que une a Hoefnagel con Ortelius (tu solus, tu primus, tu postremus mi Orteli), conviene quedarse con la evocación de la unión de
Mercurio y Minerva, del arte y la sabiduría, en una alusión típica a la espiritualidad neoestoica a la que ambos se adhieren. Ortelius, presentado como sunautopton, es el que, en el gozo del viaje por tierras italianas, ha mostrado a Hoefnagel dónde estaba su destino. El dibujante, en la serie de grabados que realiza para el Civitates orbis terrarum, deja constancia del recuerdo y se lo regala a su amigo.

\section{NOTAS}

1 Para este tema me permito remitir al lector a mi libro, Les Grandeurs de la terre. Aspects du savoir géographique à la Renaissance, Lyon, ENS Editions, 2003.

2 Julien Gracq, A lo largo del camino, Barcelona, Acantilado, 2007, trad. de C. Yepes [Carnets du grand chemin, Paris, José Corti, 1992].

${ }^{3}$ Cornelis Koeman, The History of Abraham Ortelius and his Theatrum orbis terrarum, Lausana, Sequoia, 1964; Giorgio Mangani, I/ «mondo» di Abramo Ortelio. Misticismo, geografia e collezionismo nel Rinascimento dei Paesi Bassi, Ferrara, Franco Cosimo Panini, 1998; Pierre Cockshaw y Francine de Nave (ed.) Abraham Ortelius (1527-1598), cartograaf en humanist, Museum Plantin Moretus- Koninklijke bibliotheek van België, Turnhout, Brepols Publishers, 1998; Tine Meganck, Erudite Eyes: Artists and Antiquarians in the circle of Abraham Ortelius (15271598), Princeton University, 2003.

${ }^{4}$ Véanse entre otros, Teresa Colletta, «ll 'Theatrum urbium' e I'opera di Joris Hoefnagel nel Mezzogiorno d'Italia (1577-1580)», Archivo storico per le provincie napoletane, vol. CII, 1984, pp. 45-102; Lucia Nuti, "The mapped views by Georg Hoefnagel: the merchant's eye, the humanist's eye», Word and Image, vol. 4, $n^{\circ} 2$, 1988, pp. 545-570.

${ }^{5}$ Karel Van Mander, Le livre des peintres. Vies des plus illustres peintres des Pays-Bas et d'Allemagne, París, Les Belles Lettres, vol. 2, 2002 (Haarlem, 1604), ppp. 61-66.
${ }^{6}$ Algunos de estos dibujos se encuentran en el Albertina de Viena (reproducidos en Otto Benesch (ed.), Die Zeichnungen der niederländischen Schulen des XV. und XVI. Jahrhunderts, Wien, A. Schroll, 1928).

7 Ernst Kris, "Georg Hoefnagel et le naturalisme scientifique», en Le style rustique, Paris, Macula, 2005, pp. 169191.

${ }^{8}$ Véanse Lee Hendrix, Joris Hoefnagel and the «Four éléments»: A Study in Sixteenth-Century Nature Painting, Ph.D., Princeton, 1984, y Theodora Wilberg Vignau-Schuurman, Die Emblematischen Element im Werke Joris Hoefnagels, tesis, Leiden, 1969.

${ }^{9}$ Véase Jean-Marc Besse, "Vues de ville et géographie au seizième siècle: concepts, démarches cognitives, fonctions», en F. Pousin (dir.), Figures de la ville et construction des savoirs, Paris, CNRS Editions, 2005, pp. 19-30.

10 Georg Braun, Livre troisième des villes principales du monde, Koöln, 1580, prefacio (no paginado).

11 Antoine du Pinet, Plantz, pourtraitz et descriptions de plusieurs villes et forteresses..., Lyon, 1564, p. 14.

12 Leandro Alberti, Descrittione di tutta Italia, nella quale si contiene il sito di essa, I'origine et le Signorie delle Città et delle Castelli..., Bologna, 1550. Véase Giancarlo Petrella, L'officina del geografo. La «Descrittione di tutta Italia» di Leandro Alberti e gli studi geografico-antiquari tra Quattro e Cinquecento, Milano, Vita e Pensiero, 2004 (sp. pp. 157 y ss.).

13 Véase Jean D'Amato, "Cicero's villas in the Phlegraean fields: the de- velopment of a historical and cultural myth», Viator, 24, 1993, pp. 385-419. Consúltese también el sitio web del proyecto Campania Felix (www.nsula. edu/campaniafelix/), desarrollado por Jean D'Amato y Richard Monti.

${ }^{14}$ Véanse J.-M. Besse, «Historiae oculus géographia: cartographie et histoire dans le Parergon d'Ortelius», Ecrire l'histoire, 2009, 4, pp. 137-146 ; Íd., «Philologie et cartographie au XVle siècle: la critique de l'histoire dans le Parergon et le Thesaurus geographicus d'Abraham Ortelius», en las actas del 3er Simposio Iberoamericano de Historia da Cartografia, São Paulo, 2010.

15 Arnaldo Momigliano, «L'histoire ancienne et l'antiquaire», en Problèmes d'historiographie ancienne et moderne, Paris, Gallimard, 1983, pp. 244-293.

${ }^{16}$ Nina Eugenia Serebrennikov, «Imitating nature/Imitating Bruegel», Nederlands Kunsthistorisch Jaarboek 1996, Waanders Uitgevers, Zwolle, 1997, pp. 222-246. [También de J.-M. Besse, "La tierra como paisaje: Brueghel y la geografía" en La sombra de las cosas, Madrid, Biblioteca Nueva, 2011, pp. 47-82].

17 Henri Hondius, Nouveau Théâtre du Monde..., Amsterdam, 1639, prefacio para el lector.

18 Véase acerca de esta cuestión los estudios recopilados en Perrine Galand-Hallyn, Sylvie Laigneau, Carlos Lévy, Wim Verbaal (dir.), La société des amis à Rome et dans la littérature médiévale et humaniste, Turnhout, Brepols, 2009. 


\title{
TEXTO ORIGINAL
}

\author{
Le voyage, le témoignage, l'amitié: \\ Abraham Ortelius et Georg Hoefnagel en Italie (hiver 1577-1578)
}

Jean-Marc Besse

CNRS (Centre national de la recherche scientifique), París

Dans l'interrogation sur le rôle joué par la géographie dans la formation des cultures visuelles du XVle siècle, l'analyse des rapports entre formes du regard et types de représentations de l'espace constitue un moment décisif. On connaît les relations qui existent entre, d'une part, l'apparition d'un certain genre de peintures paysagères (notamment celles qui ont été baptisées «paysages de monde» par les historiens d'art), et d'autre part l'émergence d'une nouvelle conception du globe terrestre dans les savoirs géographiques du XVle siècle, plus précisément le développement d'un nouveau concept géographique de la terre: la terre universelle ${ }^{1}$. Les représentations picturales du paysage (Bruegel, Patinir, Met de Bles) expriment à leur manière cette modification du cadre spatiotemporel de la vie humaine. Plus précisément, ce qui se joue, de manière concomitante, dans les registres de la cosmographie et de la peinture, registres pas vraiment distincts au bout du compte, c'est une transformation des conditions spatio-temporelles de l'expérience géographique, transformation assez fondamentale, au sens où elle a une portée qu'on peut dire anthropologique, correspondant à un enrichissement, décisif pour l'époque moderne, de l'idée de monde. Ce qui s'offre désormais à la vue et à la pensée, aussi bien dans les mappemondes que dans les «paysages de monde», c'est l'espace ouvert, l'horizontalité de cet espace pour ainsi dire, sa parcourabilité infinie, ses plis cachés et à découvrir, et tout simplement sa positivité narrative.

Dans la cartographie comme dans la représentation du paysage, on observe alors une même volonté de rendre compte de la profusion du monde et des expériences qu'il rend désormais possible. On observe surtout une volonté analogue, sur le plan graphique, de relier les divers aspects du monde au sein d'un espace unifié, l'espace terrestre pensé comme un tout. Et cette mise en relation générale des aspects et des lieux du monde, c'est la circulation, le déplacement, tout à la fois des hommes et des choses, qui l'effectuent. Dans ces panoramas, tout nous parle de voyage. Oiseaux et autres bêtes, navires de toute nature, véhicules, piétons et cavaliers, c'est un peuplement entier qui semble traverser de tous côtés la surface de la Terre. Le monde est un espace où l'on circule. Et ce monde lui-même est animé de mouvements réels et possibles, comme le montrent les nuages, les rivières, les chemins qui traversent les montagnes, et l'horizon ouvert.

La co-présence au sein de la série des Grands paysages de Bruegel de deux types de personnages placés dans deux parties nettement séparées de l'image, et dont les attitudes et les regards sont mis en opposition mais aussi en correspondance est, à cet égard, très significative. Ces personnages, dont les uns regardent le monde extérieur, le paysage, et les autres s'en détournent pour s'abîmer dans la contemplation d'une parole et d'une histoire supra-mondaines, et qui au fond, les uns et les autres, n'appartiennent pas au monde où ils sont vus, soit qu'ils y sont simplement des passants (pèlerins, marchands, soldats), soit qu'ils s'en excluent pour rester au désert, semblent incarner de manière exemplaire, dans leur distinction même, une interrogation sur les transformations anthropologiques et psychologiques des cadres de l'expérience géographique. Ils permettent en tout cas de poser une série de questions: pourquoi faudrait-il regarder le monde terrestre? Que faudrait-il y voir? Comment peut-on le voir? Questions qui peuvent paraître un peu générales, mais dont il semble qu'elles sont prises en charge par les personnages mêmes dont on suit les cheminements, dont on observe le repos, et surtout dont on peut suivre le regard dans l'image.

Dans ses Carnets du grand chemin, Julien Gracq rencontre une interrogation équivalente en feuilletant un recueil de gravures de Dürer². II est quasi impossible, écrit-il, de se représenter «ce qu'étaient alors [au XVle siècle] les routes, les chemins; non pas tant leur aménagement technique sommaire [...] que leur relation vivante avec les 
villes, les bourgades qu'elles joignaient, les paysages qu'elles traversaient, avec les haies et les clôtures, les bois, les cours d'eau, le mouvement aussi de leurs usagers...» (p. 184). «Comment, se demande alors Julien Gracq, voyaiton la Terre quand on allait?» (p. 185), ajoutant que jamais probablement la terre d'Europe «ne fût plus belle qu'à cette époque où «les chemins profanes [se] sont partout ouverts» (p. 186). Et il conclut: «Comme j'aurais aimé faire la route d'un de ces peintres hollandais ou allemands qui descendaient enivrés vers I'Italie...» (p. 186).

C'est un enivrement analogue qu'on voudrait suivre ici, celui d'un dessinateur et d'un géographe, Joris (ou Georg) Hoefnagel et Abraham Ortelius, tous deux flamands, tous deux amis de Bruegel et admirateurs de Dürer (Ortelius a réuni deux recueils de plusieurs dizaines de dessins et gravures du "vieux maître allemand», comme I'appelle Julien Gracq), tous deux grands voyageurs en Europe, tous deux fuyant Anvers en quelque sorte ou en tout cas désirant s'en éloigner (ce sera définitif pour Hoefnagel), à la suite du saccage de la ville par les Espagnols en novembre 1576, pour aller vers une terre, I'Italie, qui a pour eux, comme pour beaucoup d'autres, les apparences d'un lieu idéal ${ }^{3}$.

Ce voyage vers I'Italie et en Italie a eu lieu entre la fin de septembre 1577 et la fin de mars 1578 . II a mené les deux voyageurs depuis Francfort jusqu'aux abords de Naples. Mais ce que I'on sait de ce voyage place I'historien un peu dans la position de Julien Gracq vis-à-vis de Dürer: en témoignent une petite vingtaine de gravures, publiées à Cologne à partir de 1580 dans les volumes du Civitates orbis terrarum de Georg Braun et Franz Hogenberg, qui peut être considéré comme le premier véritable atlas urbain de l'époque moderne en Europe. Les dessins d'Hoefnagel ne sont pas les seuls qui représentent les villes italiennes dans le recueil de Braun et Hogenberg (celui-ci comprend plusieurs dizaines de vues de ville, publiées en six volumes en 1572 et 1618). Ils présentent cependant deux traits caractéristiques: d'une part ce sont des vues frontales et pour ainsi dire piétonnières, et non pas des vues à vol d'oiseau comme la plupart des autres vues de villes que contient le recueil, et d'autre part les vues dessinées par Hoefnagel contiennent, comme les paysages de Bruegel, des personnages occupés à des activités diverses, et dont l'artiste se présente à plusieurs reprises comme le témoin oculaire. Mais surtout, parmi ces personnages qui peuplent les images, deux individus apparaissent à plusieurs reprises, qui retiennent l'attention: il s'agit d'Ortelius et d'Hoefnagel eux-mêmes, désignés comme tels dans la légende des images, traversant le paysage italien vers le Sud. Que font-ils là dans l'image? À quoi sont-ils occupés? Que regardent les deux voyageurs dans le paysage? Telles sont les questions qu'on voudrait poser à cette série de gravures.

\section{I - Traverser l'Italie}

Quelques mots, tout d'abord, sur la réalité de ce voyage et de ses protagonistes ${ }^{4}$. Les situations respectives d'Ortelius et d'Hoefnagel n'y sont pas tout à fait comparables, en effet. En 1577, Abraham Ortelius a déjà acquis une notoriété considérable, à plusieurs titres. II est tout d'abord l'auteur d'un ouvrage qui a connu un très grand succès commercial, notamment en Italie: le Theatrum orbis terrarum, généralement considéré comme le premier atlas de forme moderne. Mais il est aussi un grand marchand d'œuvres d'art et de cartes, un érudit antiquaire et un collectionneur recherché dans plusieurs domaines: celui de la numismatique (sa collection est un modèle pour beaucoup, à l'époque), celui des arts du dessin (c'est un ami de Bruegel et de nombreux autres artistes flamands), celui enfin de la toponymie antique (il réalise trois dictionnaires considérés comme fondamentaux par ses contemporains, Juste Lipse ou John Dee en particulier). Il est tout à fait probable d'ailleurs que le séjour en Italie, durant I'automne et l'hiver 1577-1578, soit pour lui l'occasion de développer ses recherches dans ces divers secteurs. La situation de Joris (ou Georg) Hoefnagel à la même époque est assez différente. Hoefnagel appartient à l'une de ces familles anversoises de confession protestante que la Furie espagnole de 1576 a ruinée en partie, et a conduit à émigrer, vers l'Allemagne ou l'Angleterre notamment. C'est à ce moment que selon Karel Van Mander, il décide d'aller s'installer à Venise ${ }^{5}$. Mais le voyage vers I'Italie en compagnie d'Ortelius va s'avérer décisif pour le peintre et dessinateur anversois, et le conduire finalement ailleurs, à Munich d'abord, à la cour du duc de Bavière Albert V, puis à la cour de l'empereur Rodolphe II (Francfort, puis Vienne). C'est après la période du voyage en Italie que la carrière d'Hoefnagel comme miniaturiste et enlumineur de manuscrits va véritablement se développer.

En tout état de cause, le déplacement vers I'Italie va permettre à nos deux voyageurs de visiter quelques-unes des grandes collections européennes du temps: à Augsburg celle du banquier bibliophile Marx Fugger et l'importante collection de monnaies d'Adolf Occo, à Munich la collection d'œuvres d'art du duc de Bavière (grâce à une lettre d'introduction de Fugger et d'Occo), celle d'Alexandre Farnèse à Rome. La présence d'Ortelius à Ferrare le 30 octobre 1577, où il rencontre Pirro Ligorio, est attestée. On parle aussi d'un passage par Florence. Un passage également par la collection de l'archiduc Ferdinand II au château d'Ambras à Innsbruck ne paraît pas impossible, ni une visite à Caprarola. 
En dehors du récit de Van Mander, la réalité effective du trajet et du séjour reste difficile à établir. Certes, on dispose de quelques dates qui permettent d'encadrer les hypothèses: Ortelius se trouve le 20 septembre à Francfort, le 7 octobre à Augsburg et le 30 à Ferrare (selon les inscriptions de son Album amicorum), Hoefnagel est le 24 décembre à Pesaro et le 20 avril 1578 de retour à Munich (ce qu'il note lui-même sur les dessins préparatoires aux gravures $\left.{ }^{6}\right)$. Les deux hommes visitent ensemble Tivoli le 1 er février 1578 , s'il faut en croire l'inscription qui est portée sur la gravure publiée dans le Civitates orbis terrarum.

Au bout du compte, la principale source sur laquelle il est possible de s'appuyer pour suivre le voyage est constituée par la série de gravures publiée dans le recueil de Braun et Hogenberg. Une série qui présente évidemment un biais: I'ordre dans lequel les images sont présentées au sein du recueil ne correspond sans doute pas au déroulement effectif du déplacement, notamment dans la partie qui concerne I'Italie du Nord, sur laquelle il y a beaucoup d'incertitudes: nos deux voyageurs sont-ils allés ensemble vers Rome en suivant la voie Flaminienne? Ou bien se sont-ils séparés (on note qu'Hoefnagel indique, au bas de la gravure représentant l'incendie du Palais des Doges à Venise, qu'il en a été le témoin; or cet incendie a eu lieu le 20 décembre 1577, cela donnerait une sorte de cohérence à la date du 24 décembre pour la vue de Pesaro)? Ou bien encore ne peut-on pas dire qu'Hoefnagel a profité du séjour à Rome pour aller sur le terrain (ce qui semble le plus probable, notamment parce que les villes qu'ils représentent sont situées sur des routes différentes et qu'on voit mal nos voyageurs adopter un tel comportement erratique)? Autrement dit, il faut faire la différence entre le voyage réel et le voyage imaginaire qui est ordonné par la succession des vues dans le Civitates orbis terrarum. La logique géographique qui s'y déploie est surtout une logique éditoriale et descriptive sous-tendue par une conception de l'espace centrée sur le Nord de l'Europe, dont le lecteur est censé partir, pour aller, dans le cas de l'Italie, vers le Sud. Le seul «moment» où le voyage réel et le voyage d'images semblent se superposer est celui qui conduit Ortelius et Hoefnagel de Rome à la région de Naples, par la voie Appienne. C'est aussi le seul moment où l'on voit, de manière significative, nos voyageurs à l'intérieur des images, engagés dans des activités diverses par rapport au paysage. Revenons alors à nos questions: que font Ortelius et Hoefnagel dans l'image? À quoi sont-ils occupés précisément? Que regardentils dans le paysage?

Pour envisager ces questions on peut dans un premier temps s'appuyer sur une distinction assez sommaire entre deux catégories de personnages présents dans les images: d'une part les personnages qui sont vus par les voyageurs, qui sont montrés comme des objets sous les regards des voyageurs, et d'autre part les voyageurs euxmêmes, en l'occurrence les voyageurs anversois, qui sont montrés comme des regardants, des sujets regardants. Distinction du regardé et du regardant, de l'objet et du sujet, qui accompagne et exprime peut-être une autre distinction, celle du dedans et du dehors. Autrement dit: une distinction entre les personnages qui sont vus comme appartenant au paysage, quelle que soit l'activité qu'ils y développent, et les personnages qui n'y appartiennent pas, qui viennent d'ailleurs, de l'extérieur, et qui ne font que passer.

\section{II - Regarder I'Italie}

Qui voit--on dans les images d'Hoefnagel [ILLUSTRATIONS 1]? Quels sont les personnages qui, dans l'image, sont du côté de ce qui est regardé, comme appartenant aux lieux traversés? On peut en faire rapidement l'inventaire typologique: ce sont des marins, des pêcheurs, des porteurs, des bergers, des agriculteurs, des femmes engagées dans des activités diverses (se rendre au marché ou en revenir, cueillir les olives, aller aux bains), des porteurs, des mendiants, des voyageurs, plus généralement des personnes qui circulent dans le territoire avec ou sans animaux, des touristes peut-être, des scènes galantes ou un peu énigmatiques, des vendeurs d'objets archéologiques...

Ces divers groupes humains contribuent à animer et surtout à caractériser les paysages dans lesquels ils sont vus. Une précision: tous ces personnages, sauf exception (Venise) ne sont pas vus dans la ville, qui constitue pourtant le centre de l'image et qui en est la raison d'être. Ils en sortent ou ils y entrent, ils sont occupés à diverses tâches autour de la cité. Ils appartiennent au territoire. En ce sens, on peut parler d'une sorte de «naturalisation» des activités humaines dans les descriptions graphiques réalisées par Hoefnagel. II faudrait cependant préciser le sens de cette expression. On a souvent mentionné en effet, à la suite de l'article d'Ernst Kris sur Hoefnagel et le naturalisme scientifique, le réalisme et le didactisme des vues topographiques du dessinateur flamand ${ }^{7}$. La dimension de l'autopsie, du témoignage visuel, du «pris sur le vif», de l'expérience vécue, est souvent présente dans les légendes des dessins d'Hoefnagel, qui lors de ses voyages, comme l'écrit Van Mander, avait fait «un très gros volume de tout ce qui le frappait: des scènes rustiques, des pressoirs, des travaux hydrauliques, des scènes de mœurs: mariages, danses, fêtes, etc.» (p. 62). C'est le cas en Italie. C'était aussi le cas pour les nombreux dessins réalisés en Espagne que l'on trouve également dans le Civitates orbis terrarum. 
On n'entrera pas ici dans le commentaire de la signification de la devise Natura sola magistra (la nature est mon seul maître) utilisée par Hoefnage ${ }^{8}$. On voudrait surtout réinsérer les images du dessinateur flamand dans le contexte du projet intellectuel et éditorial où elles ont été rendues publiques, après avoir été commandées pour la plupart, c'est-à-dire celui du Civitates orbis terrarum. Ce projet est énoncé très explicitement par le concepteur de I'ouvrage, Georg Braun en référence au Theatrum orbis terrarum d'Ortelius d'ailleurs, mais surtout dans le cadre d'une distinction conceptuelle qui reste encore celle de Ptolémée: la distinction entre la géographie et la chorographie. L'atlas d'Ortelius est un ouvrage de géographie, au sens où il a pour objectif la représentation du monde terrestre à petite échelle, celle de la mappemonde. Prétendant se placer aux côtés du Theatrum orbis terrarum, et dans une sorte de parallèle avec lui, I'ouvrage de Braun et Hogenberg (Civitates orbis terrarum) a l'ambition de prendre en charge la représentation du monde à grande échelle, c'est-à-dire au niveau des lieux. Cette échelle est celle de la chorographie et de la topographie (les deux mots se recouvrent en partie). Autrement dit, si Ortelius est géographe ou cosmographe, Hoefnagel sera chorographe ou topographe.

La distinction entre géographie et chorographie (ou topographie) n'est pas seulement une distinction d'échelle (le global/le local) ${ }^{9}$. Elle renvoie aussi à un principe de méthode et à une pratique différenciée de la représentation. L'approche géographique, dit-on alors à la suite de Ptolémée, est géométrique, elle se préoccupe de l'exactitude des localisations, des distances entre les lieux, et de la conformité dans le dessin des limites et des formes des territoires. Selon le vocabulaire de l'époque, tout ceci relève d'un souci qui est celui de la quantité. L'approche chorographique est différente. Elle cherche à représenter les qualités caractéristiques d'un lieu, ses propriétés singulières, selon une méthode qui est celle du portrait, en «exposant en particulier, comme le dit Braun dans la préface au livre III, I'histoire de certaines parties du monde, [...] les mettant devant les yeux des regardants, comme s'ils regardoient les lieux mesmes» ${ }^{10}$, ou bien, comme le dit un contemporain, Antoine du Pinet, "en montrant seulement à l'œil, le plus près du vif qu'elle peut, la forme, l'assiette, \& les dependances du lieu qu'elle depeint: comme seroyent les Fortz, Cittadelles, Temples, Rues, Colysees, Arenes, Places, Canaux, Viviers, Havres, Moles, \& autres bastimens de marque qui pourroyent estre en une ville, avec le païsage d'alentour, \& les traffiques d'icelle. ${ }^{11}$ » Si le géographe ou le cosmographe considère le globe terrestre de loin, depuis le ciel pour ainsi dire, le chorographe cherche à voir les lieux de près.

Revenons aux personnages d'Hoefnagel. Mais, pour y revenir et en comprendre la présence, arrêtons-nous à l'expression «païsage d'alentour» d'une ville, utilisée par Du Pinet. Le même Du Pinet, un peu plus loin, parlera du «païsage d'un lieu» et du "païsage d'un païs». Le mot «païsage» n'a pas ici une signification spécialement artistique, même s'il peut être pris en charge par le dessin et la peinture. II désigne un espace visible, ou plus précisément l'aspect ou plutôt les aspects visibles du pays, du lieu ou du territoire qui entoure la ville, l'ager et peut-être le saltus, par opposition à l'urbs. II renvoie à ce qu'un voyageur et un observateur peuvent rencontrer lorsqu'ils circulent dans le lieu ou le pays: une géologie, des accidents de sol, des couleurs, des champs cultivés, des routes, des villes, des maisons, des vestiges du passé, des êtres humains. Signalons, sans pouvoir nous y arrêter, que les images d'Hoefnagel sont accompagnées d'un texte qui vient expliciter ce qu'on y peut découvrir. Un texte généralement compilé à partir de la description d'Italie de Leandro Alberti, et qui donne au lieu représenté une sorte d'épaisseur historique ou mythologique ${ }^{12}$.

Le paysage dessiné par Hoefnagel est donc aussi un espace vécu, travaillé, construit, traversé, bref l'espace d'un ensemble de vies ordinaires: un paysage humain, et pas seulement une topographie naturelle ou un spectacle grandiose. Les personnages représentés font partie du paysage, mais parce qu'ils habitent et caractérisent un espace (celui de l'Italie en l'occurrence) qui est également vécu par le dessinateur qui le sillonne.

Autrement dit, les images d'Hoefnagel développent une conception de l'espace (et du paysage) qu'on peut dire chorographique (plutôt que géographique au sens strict du terme): on n'a pas affaire, comme dans le cas de la cosmographie ou de la géographie à un regard surplombant sur la terre, mais plutôt à une vision ou une construction de l'espace terrestre qui se fait de proche en proche, à ras du sol si l'on peut dire, à partir des lieux traversés et vus de près par l'homo viator. L'espace des paysages d'Hoefnagel est une collection de lieux, d'accidents, de singularités. Les personnages qui s'y trouvent font partie de ces singularités qui donnent au paysage sa densité particulière.

\section{III - Critiquer I'Italie?}

Qu'en est-il, alors, des personnages qui, dans les images sont montrés comme n'appartenant pas aux lieux et aux paysages où ils sont vus? Qu'en est-il de ceux qui passent? Qu'en est-il en particulier des voyageurs que 
sont Abraham Ortelius et Joris Hoefnagel? Comme on l'a déjà signalé, c'est surtout le trajet de Rome à Naples et le séjour en Campanie qui sont documentés par Hoefnagel. Revenons encore une fois à nos questions initiales, qu'il est possible maintenant de poser aux images qui les représentent: que font nos voyageurs flamands dans ces images? à quoi sont-ils occupés en Italie?

Une première réponse serait la suivante: ils s'occupent à bien des choses différentes [ILLUSTRATIONS 2]. Ils dessinent (Vérone), ils bavardent (Velletri, Naples), ils admirent (Pozzuoli, Gaëte), ils font des observations et des expériences (Lac d'Agnano), ou bien ils commémorent (Tivoli). Les deux voyageurs flamands visitent I'Italie sur le mode du loisir érudit, propre peut-être aux antiquaires du XVle siècle. Pourtant, le regard qu'Ortelius et Hoefnagel portent sur la Campanie est plus complexe qu'il n'y parait.

C'est un regard double en effet, qui mêle les souvenirs de lecture et les observations sur le terrain, lectures et observations se contredisant parfois. Regard ambivalent par conséquent, où, au plaisir de parcourir concrètement une terre légendaire, l'expérience même des lieux ajoute l'argument d'une prise de distance critique.

D'un côté donc, c'est la joie d'être là qui s'exprime dans les images, l'admiration voire l'adoration qui se voit dans les attitudes des personnages, et dans les légendes qu'ils donnent à lire. Ortelius et Hoefnagel s'inscrivent sans détours dans le topos de la Campania felix [ILLUSTRATION 3], comme l'indique le texte qui donne son titre à la vue de Baia: Nullus in Orbe Locus Baijs praelucet amoenis (l'édition en langue française de 1618 traduit: «ll n'y a lieu au monde a preferer a Baye la plaisante»).

Mais d'un autre côté, le regard se fait plus inquisiteur, plus observateur, plus expérimental, marquant ainsi une sorte de prise de distance critique avec les traditions de l'Antiquité. On le voit en particulier dans la planche qui présente deux vues, le Lac d'Agnano d'une part et Cumes d'autre part, connue pour accueillir l'antre de la Sybille [ILLUSTRATIONS 4].

Dans le cadre supérieur, le texte indique que le nom du lac vient du grec aorgnon, qui signifie «sans oiseaux». Selon Virgile, l'absence d'oiseaux est due aux fumées mortelles qui s'élèvent du lac, dont on pensait qu'il était l'entrée des enfers, fumées qui auraient donc le pouvoir de tuer les oiseaux passant au-dessus de l'eau' ${ }^{13}$. Au centre de l'image se tiennent les deux voyageurs, l'un pointant du doigt des oiseaux nageant sur le lac, tandis que l'autre prend des notes, peut-être celles qu'on lit à leur droite ou dans le commentaire qui accompagne la planche: Ortelius et Hoefnagel «ont connu par certaine expérience que ce lac n'est pas aorgnon». L'observation sur le terrain vient contredire le texte de Virgile.

Il faudrait sans doute mettre en rapport ce double regard avec l'attitude adoptée par Ortelius dans le domaine de l'histoire et des savoirs antiquaires. On y retrouve le même type d'ambivalence vis-à-vis du passé tel qu'il est lu dans les textes anciens.

D’un côté en effet, la carte (et plus généralement l'image géographique) est définie comme un instrument qui permet de lire et de comprendre les histoires (c'est le sens de la formule d'Ortelius qui se trouve au début du Theatrum orbis terrarum ou dans le frontispice du Parergon: la géographie est l'œil de l'histoire). En ce sens l'image géographique, parce qu'elle est un outil de visualisation de l'histoire, est un support pour l'attestation du récit. L'image fait preuve de ce que dit le texte. On retrouve cette conception des relations entre image, géographie et histoire, à l'œuvre par exemple dans la vue qui représente Ortelius et Hoefnagel de dos, devant le golfe de Gaëte, Ortelius montrant du doigt à son compagnon un cartouche sur lequel se lit une phrase extraite du début du Livre 7 de l'Enéide de Virgile: Tu quoque litoribus nostris, Aeneia nutrix, aeternam moriens famam, Caieta, dedisti («Toi aussi, Caiète, nourrice d'Énée, par ta mort/tu as donné à nos rivages une gloire éternelle»: au sortir des Enfers, Énée quitte la Campanie et va mouiller dans un port du sud du Latium, auquel il donne le nom de Caiète, en I'honneur de sa nourrice Caieta, qui vient de mourir) [ILLUSTRATION 5]. L'image montre le lieu dont il s'agit dans le texte, elle est sous la dépendance du texte historico-poétique de Virgile, auquel d'une certaine manière Ortelius et Hoefnagel demandent au lecteur de se conformer en imagination.

Mais d'un autre côté Ortelius met en œuvre d'autres stratégies iconographiques, où l'on assiste plutôt à une véritable reconnaissance de l'image comme support spécifique, voire exclusif, de l'information historique ${ }^{14}$. Cette «libération» de l'image s'est effectuée, d'abord, mais pas exclusivement, dans le domaine de la numismatique. Ortelius numismate, mais aussi éditeur de cartes historiques, est engagé, avec d'autres, du côté de l'élargissement du domaine des sources historiques. Les monnaies, en effet, permettent de comprendre le sens d'un mot, ou d'une activité, ou de tout autre chose, par comparaison du texte où ils ont été lus avec l'image qui la représente. Elles sont comme des traces ou des vestiges du passé, dont on peut alors s'assurer qu'il n'est pas une simple fiction. En outre, parce qu'elles montrent les objets décrits dans les textes anciens, les monnaies en réaniment la 
mémoire perdue, et les restituent, pour ainsi dire, au domaine de l'expérience possible.Mais surtout, les monnaies, ainsi que les images gravées qui les représentent et les mettent en circulation dans le monde savant, fournissent à l'historien des informations qu'il ne trouve pas ailleurs. Si, comme l'a indiqué Momigliano dans un article classique, «l'idée que l'on puisse écrire une histoire de Rome capable de remplacer Tite-Live et Tacite [n'est] pas encore née»à cette époque ${ }^{15}$, il reste qu'il n'est pas impossible de travailler dans les marges des textes anciens, et d'y insérer des informations nouvelles, issues de l'observation de terrain. Même, il n'est pas impossible de faire preuve d'audace et de liberté par rapport au passé. On peut se demander si ce n'est pas ce qu'indiquent les attitudes des personnages de la planche qui les montrent inspectant le lac d'Agnano, y faisant des expériences et bravant la menace qui se dresse devant la porte de la grotte de la Sybille (cf. illustration 4).

En tout état de cause, les quelques images qui mettent en scène Ortelius et Hoefnagel dans les paysages de la Campanie signalent que le rapport qu'ils entretiennent avec les lieux et les paysages de l'Antiquité n'est plus si simple: certes il faut y aller voir et ils se réjouissent d'y être, mais, en même temps, l'écart apparaît entre ce qu'ils voient et ce qu'ils savaient, entre ce que les livres leur avaient appris et ce que les lieux eux-mêmes leur disent désormais directement.

\section{IV - Être allé en Italie}

Cependant, les images que nous sommes en train de contempler nous montrent aussi d'autres regards.

Ainsi y voit-on, par exemple, Hoefnagel, qui se regarde lui-même pour ainsi dire, ou plutôt qui se montre dans la revendication de son identité d'artiste, notamment dans son rapport à Bruegel, à Tivoli ${ }^{16}$. Ces gravures ne parlent donc pas seulement de l'Italie du XVle siècle, ni d'un certain type de rapport à établir avec le passé antique, elles parlent aussi d'amitié et de la définition d'un certain type d'ethos savant, incarné ici par Ortelius devant Hoefnagel.

La vue de Velletri est, à cet égard, très significative [ILLUSTRATION 6]. Elle montre Ortelius et Hoefnagel s'approchant de la ville, durant la première journée du voyage de Rome à Naples (selon l'indication portée sur le dessin original). Les deux hommes, qui à ce moment ne regardent pas le paysage mais sont tournés l'un vers l'autre, sont en grande discussion apparemment. L'un (qui semble plus âgé, Ortelius sans doute) désigne le ciel de l'index de la main gauche, l'autre a l'index de la main droite pointé vers le sol ou, plus exactement, vers le chemin qu'ils sont en train de suivre. Faut-il y voir, de la part du dessinateur (c'est-à-dire d'Hoefnagel), une allusion à la discussion philosophique entre Platon et Aristote mise en scène par Raphaël au Vatican, et qu'ils ont pu connaître? Faut-il voir un débat, sur cette route qui s'approche de la ville, concernant les directions qu'il faut donner au regard et à la pensée? Le ciel ou la terre? Une réflexion sur la fabrication et l'ordre du cosmos, ou bien une interrogation sur les règles de vie à suivre sur cette terre? Une méditation cosmographique ou bien une délibération éthique? Quel chemin suivre, au bout du compte?

II n'est pas sûr qu'il faille choisir. Il est possible que ce soit la coexistence entre ces deux directions qui donne le sens exact de la situation humaine et, surtout, de la situation cognitive dont il s'agit dans cette image. II est frappant en effet de mettre en rapport ce qui se dessine ou se discute par ces mouvements de bras et de regards dans le paysage italien, avec les réflexions contemporaines sur la situation et la pratique de la géographie elle-même. Car en fait, la mise en relation du ciel et de la terre, sur le plan mathématique et physique, constitue précisément I'enjeu même de la cosmographie dans les définitions qu'on lui donne au XVle siècle. Un regard unifiant qui est un regard alterné, montant d'abord vers le Ciel, redescendant ensuite vers la Terre pour en déterminer la figure exacte juste. Henry Hondius a défini l'espace du travail de la cosmographie en résumant, à sa manière, l'alternative mise sous nos yeux devant Velletri:

Dieu nous a colloqués sur la Terre et au-dessous du Ciel; afin que tantost en baissant la face nous regardissions la Terre, tantost levant les yeux nous contemplassions le Ciel. En regardant en haut et considérant attentivement ceste admirable machine des Sphères célestes nous devenons Astronomes. En baissant nostre veuë vers la Terre, et nous occupans à mesurer son estendue, nous sommes Geographes. Par ces deux Sciences l'homme se rend digne habitant du monde... ${ }^{17}$

La même nécessité de penser ensemble le ciel et la terre, dans le cadre de la cosmographie, s'exprime également dans le frontispice de l'édition de Ptolémée réalisée en 1578 par Gérard Mercator. Considérons en effet les gestes effectués par Ptolémée, le prince des géographes, à gauche de l'image, tel qu'il est représenté par celui qu'on appellera le Ptolémée moderne [ILLUSTRATION 7]. 
La main gauche désigne en bas le globe terrestre par le moyen du compas qui le mesure. L'index de la main droite est levé vers le haut et désigne très précisément le globe céleste (avec les images des constellations), qui est le fondement des mesures terrestres. Ces deux bras sont comme deux regards. Le cosmographe est celui qui relie, comme un intercesseur, dans l'espace même ouvert par ses bras, les deux globes. Le corps même du cosmographe, dans l'image, est le lieu où s'inscrit pour le regard du lecteur futur l'espace perceptif et intellectuel de la cosmographie.

Comment comprendre, au bout du compte, cette attitude d'Ortelius et d'Hoefnagel devant Velletri? Pourquoi Hoefnagel a-t-il choisi de représenter ainsi son compagnon?

L'hypothèse qu'on proposera, en guise de réponse, est la suivante: Hoefnagel est en train de dresser, dans cette image et dans la série qui retrace le séjour en Campanie, un monument d'amitié pour Ortelius ${ }^{18}$. Plusieurs indices renforcent cette hypothèse. Les textes eux-mêmes d'abord, placés par Hoefnagel sous les portraits d'Ortelius. À Gaëte, Ortelius, décrit comme un compagnon de voyage très agréable, est surtout studiosus contemplator, une expression qui détermine ici le type de regard qu'Ortelius porterait sur les paysages traversés et sur le monde en général, et qu'il faudrait sans doute mettre en relation avec les analogies déployées par d'autres amis du géographe flamand pour le désigner, et notamment avec l'image d'Apollon. Cette image apollinienne est fréquemment utilisée pour représenter le travail du cosmographe au XVle siècle, et Ortelius lui-même I'utilisera dans le Parergon, son recueil de cartographie historique.

La planche qui représente Baia, envoyée en cadeau en mars 1580 par Hoefnagel à Ortelius, contient dans sa partie centrale un texte qui mériterait un long commentaire (cf. illustration 3). Au-delà, en effet, de l'affirmation de l'amitié qui lie Hoefnagel à Ortelius (tu solus, tu primus, tu postremus mi Orteli), il faut retenir l'évocation de l'union de Mercure et Minerve, de l'art et de la sagesse, dans une allusion typique à la spiritualité néo-stoïcienne à laquelle ils adhèrent l'un et l'autre. Ortelius, présenté comme sunautopton, est celui qui, dans la joie du voyage en terre d'Italie, a montré à Hoefnagel où était son destin. Le dessinateur, dans la série de gravures qu'il réalise pour le Civitates orbis terrarum, en marque le souvenir, et l'offre à son ami. 


\section{NOTES}

1 Je me permets de renvoyer sur ce point à Jean-Marc Besse, Les Grandeurs de la terre. Aspects du savoir géographique à la Renaissance, Lyon, ENS Editions, 2003.

2 Julien Gracq, Carnets du grand chemin, Paris, José Corti, 1992.

${ }^{3}$ Cornelis Koeman, The History of Abraham Ortelius and his Theatrum orbis terrarum, Lausanne, Sequoia, 1964; Giorgio Mangani, // «mondo» di Abramo Ortelio. Misticismo, geografia e collezionismo nel Rinascimento dei Paesi Bassi, Ferrara, Franco Cosimo Panini, 1998; Pierre Cockshaw et Francine de Nave (eds) Abraham Ortelius (1527-1598), cartograaf en humanist, Museum Plantin Moretus- Koninklijke bibliotheek van België, Turnhout, Brepols Publishers, 1998; Tine Meganck, Erudite Eyes: Artists and Antiquarians in the circle of Abraham Ortelius (15271598), Princeton University, 2003.

${ }^{4}$ Voir, entre autres, Teresa Colletta, «Il 'Theatrum urbium' e l'opera di Joris Hoefnagel nel Mezzogiorno d'Italia (1577-1580)», Archivo storico per le provincie napoletane, vol. Cll, 1984, pp. 45-102; Lucia Nuti, «The mapped views by Georg Hoefnagel: the merchant's eye, the humanist's eye», Word and Image, vol. 4, n², 1988, pp. 545-570.

${ }^{5}$ Karel Van Mander, Le livre des peintres. Vies des plus illustres peintres des Pays-Bas et d'Allemagne, Paris, Les Belles Lettres, vol. 2, 2002 (Haarlem, 1604), pp. 61-66.

${ }^{6}$ Quelques-uns de ces dessins se trouvent à l'Albertina de Vienne (reproduits dans Otto Benesch (ed.), Die Zeichnungen der niederländischen Schulen des XV. und XVI. Jahrhunderts, Wien, A. Schroll, 1928).

7 Ernst Kris, "Georg Hoefnagel et le naturalisme scientifique», dans Le style rustique, Paris, Macula, 2005, pp. 169-191.

${ }^{8}$ Voir Lee Hendrix, Joris Hoefnagel and the «Four éléments»: A Study in Sixteenth-Century Nature Painting, Ph.D., Princeton, 1984, et Theodora Wilberg Vignau-Schuurman, Die Emblematischen Element im Werke Joris Hoefnagels, Thèse, Leyde, 1969.

${ }^{9}$ Cf. Jean-Marc Besse, «Vues de ville et géographie au seizième siècle: concepts, démarches cognitives, fonctions», dans F. Pousin (dir.), Figures de la ville et construction des savoirs, Paris, CNRS Editions, 2005, pp.19-30.

10 Georg Braun, Livre troisième des villes principales du monde, Cologne, 1580, préface (non paginée).

${ }^{11}$ Antoine du Pinet, Plantz, pourtraitz et descriptions de plusieurs villes et forteresses..., Lyon 1564, p. 14.

12 Leandro Alberti, Descrittione di tutta Italia, nella quale si contiene il sito di essa, l'origine et le Signorie delle Città et delle Castelli..., Bologna, 1550. Voir Giancarlo Petrella, L'officina del geografo. La «Descrittione di tutta Italia» di Leandro Alberti e gli studi geografico-antiquari tra Quattro e Cinquecento, Milan, Vita e Pensiero, 2004 (sp. pp. 157 et suivantes).

13 Voir Jean D'Amato, «Cicero's villas in the Phlegraean fields: the development of a historical and cultural myth», Viator, 24, 1993, pp. 385-419.
A consulter aussi le site du projet Campania Felix (www.nsula.edu/campaniafelix), développé par Jean D'Amato et Richard Monti.

${ }^{14}$ Voir J.-M. Besse, «Historiae oculus géographia: cartographie et histoire dans le Parergon d'Ortelius», Ecrire l'histoire, 2009, 4, pp. 137-146; Id., «Philologie et cartographie au XVIe siècle: la critique de l'histoire dans le Parergon et le Thesaurus geographicus d'Abraham Ortelius», dans Actes du 3e Simposio Iberoamericano de Historia da Cartografia, Sao Paulo, 2010.

15 Arnaldo Momigliano, «L'histoire ancienne et l'antiquaire», dans Problèmes $d$ 'historiographie ancienne et moderne, Paris, Gallimard, 1983, pp. 244-293.

${ }^{16}$ Nina Eugenia Serebrennikov, «Imitating nature/Imitating Bruegel», Nederlands Kunsthistorisch Jaarboek 1996, Waanders Uitgevers, Zwolle, 1997, pp. 222-246. [Et aussi J.-M. Besse, «La tierra como paisaje: Brueghel y la geografía» en La sombra de las cosas, Madrid, Biblioteca Nueva, 2011, pp. 47-82].

17 HenriHondius, Nouveau Théâtre du Monde ..., Amsterdam, 1639, préface au lecteur.

18 Voir sur ce point les études rassemblées dans Perrine Galand-Hallyn, Sylvie Laigneau, Carlos Lévy, Wim Verbaal (dir.), La société des amis à Rome et dans la littérature médiévale et humaniste, Turnhout, Brepols, 2009. 